\title{
QUEEN'S
UNIVERSITY
BELFAST
}

\section{We Don't Train in Vain: A Systematic Review and Meta-Analysis of Human and Canine Caregiver Training}

Pfaller-Sadovsky, N., Medina, L., Dillenburger, K., \& Hurtado-Parrado, C. (2019). We Don't Train in Vain: A Systematic Review and Meta-Analysis of Human and Canine Caregiver Training. Journal of Applied Animal Welfare Science, 1-67. https://doi.org/10.1080/10888705.2019.1646134

Published in:

Journal of Applied Animal Welfare Science

Document Version:

Peer reviewed version

Queen's University Belfast - Research Portal:

Link to publication record in Queen's University Belfast Research Portal

\section{General rights}

Copyright for the publications made accessible via the Queen's University Belfast Research Portal is retained by the author(s) and / or other copyright owners and it is a condition of accessing these publications that users recognise and abide by the legal requirements associated with these rights.

Take down policy

The Research Portal is Queen's institutional repository that provides access to Queen's research output. Every effort has been made to ensure that content in the Research Portal does not infringe any person's rights, or applicable UK laws. If you discover content in the Research Portal that you believe breaches copyright or violates any law, please contact openaccess@qub.ac.uk. 
This is an Accepted Manuscript of an article published by Taylor \& Francis in JOURNAL OF APPLIED ANIMAL WELFARE SIENCE in 2019, available online: https://doi.org/10.1080/10888705.2019.1646134

\title{
We Don't Train in Vain: A Systematic Review and Meta-Analysis of Human and Canine Caregiver Training
}

\author{
Nicole Pfaller-Sadovsky ${ }^{a^{*}}$, Lucia Medina ${ }^{\mathrm{b}}$, Karola Dillenburger ${ }^{\mathrm{a}}$, Camilo \\ Hurtado-Parrado ${ }^{\mathrm{c}}$
}

a Centre for Behaviour Analysis, School of Social Science, Education and Social Work, Queen's University Belfast, United Kingdom

b Animal Behavior Laboratory, Fundación Universitaria Konrad Lorenz, Bogotá, Colombia

c Department of Psychology, Troy University, AL, United States of America

* Correspondence should be addressed to Nicole Pfaller-Sadovsky, Neunkirchnerstrasse 120, A-2734 Puchberg am Schneeberg, Austria

E-mail:npfaller01@qub.ac.uk 


\title{
We Don't Train in Vain: A Systematic Review and Meta-Analysis of Human and Canine Caregiver Training
}

\begin{abstract}
A meta-analytic review was conducted to assess the current knowledge regarding caregiver training effectiveness for human-human and human-canine dyads. The results showed that most canine-related sources $(66 \% ; n=19)$ were case studies reporting a decrease of learner undesired behavior when using oral instruction/advice $(21 \% ; n=6)$. Most of the human-related research used singlecase designs $(57 \% ; n=26)$ reporting an increase in desired learner behavior $(22 \% ; n=10)$ when caregivers received multi-component training packages, including two or more approaches $(17 \%, \mathrm{n}=8)$. The meta-analysis of betweengroup-design studies $(n=18)$ revealed that interventions had a large effect (Hedges' $\mathrm{g}=0.88,95 \% \mathrm{CI}[0.68-1.07]$ ), with packages yielding a slightly larger moderate effect (Hedges' $\mathrm{g}=0.76,95 \% \mathrm{CI}[0.60-0.91]$ ) than oral instruction/advice alone (Hedges' $\mathrm{g}=0.74,95 \% \mathrm{CI}[0.32-1,15])$. Although the shown effectiveness of caregiver training is promising, the results should be interpreted cautiously. Due to the preponderance of case studies within caninerelated literature and the insufficient reporting of data across sources, only few studies could be included in the meta-analysis. Overall, more systematic and comparative research regarding the efficacy of caregivers in behavior change programs across species is needed. 174 words
\end{abstract}

Keywords: systematic-review; human-dog relationship; caregiver-training; interventions

\section{Introduction}

Of all companion animals, dogs (Canis lupus familiaris) have been associated with humans for the longest period (Clutton-Brock, 1995). Primary association between humans and early wolves most likely began 32,000 years ago (Thalmann et al., 2013). Dogs play an astonishing range of roles in human society, including affecting social interactions, lifestyles and economics (Hart, 1995; Schöberl et al., 2012; Udell \& Wynne, 2008). Despite their overall positive impact on human well-being and health (Heady \& Grabka, 2007; Westgarth, 
Christley \& Christian, 2014; Westgarth, Christian \& Christley, 2015), companion dogs can just like humans - display unwanted behaviors. These are typically behaviors that either occur too often (i.e., behavioral excesses) or not often enough (i.e., behavioral deficits - Pierce \& Cheney, 2013). Behavioral issues can be categorized by their topography and ownerperceived severity, such as "undesirable behaviors" which owners find unpleasant (e.g., tail chasing or destructiveness), and "problem behaviors" which are difficult to overcome for the owners (e.g., inter- and intraspecific aggression, excessive barking, and fear and anxiety Pirrone et al., 2015). Both categories can create socially significant problems for the individuals themselves and/or their caregivers (Edwards \& Poling, 2011), and may result in a breakdown of the human-dog relationship with the dog being at risk for relinquishment (Kwan \& Bain, 2013; Wells \& Hepper, 2000).

Yet, canine-related research only recently started to focus on the importance of caregivers for the implementation of interventions (e.g., Echterling-Savage et al., 2014; Howard \& DiGennaro-Reed, 2014). This is surprising on at least two respects. First, the importance and efficacy of caregivers' as interventionists are well documented in the humanrelated literature. For instance, Fukkink \& Lont (2007) reviewed studies published from 1980 to 2005 demonstrating that specialized training improved the competencies of caregivers in general childcare skills, independent of the educational level of caregivers, and the setting of the trainings. Second, some research already pointed to the notion that caregiver education and training is protective against companion-animal relinquishment and resulting welfare implications, for instance a breakdown of the human-companion animal bond (Diesel, Brodbelt \& Pfeiffer, 2010; Diesel, Pfeiffer \& Brodbelt, 2008; Houpt, Honig \& Reisner, 1996). However, only few studies investigated caregiver-training interventions with respect to effectiveness and reduction or prevention of companion-dog relinquishment, as Coe et al. (2014) have found. Their scoping review highlighted that although caregiver education was the most commonly recommended intervention, the majority of studies focused on 
understanding the reasons for companion-animal relinquishment using mostly observational or survey-based methods. These findings underscore the notion that while caregiver education may be frequently recommended, it is not necessarily the most commonly applied or implemented one. Further in this vein, Coe et al. (2014) emphasized the need for primary research investigating the effectiveness of caregiver-training interventions on relinquishments and suggested the periodic update of respective systematic literature reviews and metaanalyses.

Correspondingly, the primary aim of the current study was to assess and compare existing literature involving caregiver training within human-canine and human-human dyads. To achieve this, effect size computations for caregiver and learner behavior change were conducted based on the different interventions used. Possible explanations for the differing effectiveness of interventions were provided, leading to further research suggestions related to canine-caregiver training. To the authors' knowledge this is the first meta-analytic review that attempted this task.

\section{Method}

A systematic literature review and meta-analysis was carried out. The systematic review included between-group designs ("group designs"), case studies, and single-case designs (“SCDs"). The meta-analytic part, however, included group designs only because most canine-human-interaction studies were based on group designs (or case studies). Group designs (e.g., randomized-controlled trials) share a set of distinctive characteristics, such as (a) recruitment of as large number of participants as is practicable; (b) often random allocation of the participants to treatments; (c) aggregation of individual data in averages and other group descriptors (i.e., between-subject averaging); and (d) drawing of inferences about populations from evidence gained from samples (Blampied, 1999; Hurtado-Parrado \& LopezLopez, 2015; Johnston \& Pennypacker, 1993). Case studies, on the other hand, are of more 
qualitative nature. They often describe in great detail the assessment and/or treatment of one or more participants by integrating all information about the case into a unified and related idea or set of ideas (Sturmey, 2009; Virues-Ortega \& Moreno-Rodriguez, 2008). Further, their interest is frequently related to reporting new findings that lack replication with group designs, hence, informing about new methods, novel applications of established techniques or unpredicted effects of assessments or treatments (Virues-Ortega \& Moreno-Rodriguez, 2008). By contrast, SCDs are special adaptations of interrupted time-series designs and provide a strong basis for establishing causal, or functional, inference by (a) operationally defining the dependent variable; (b) conducting baseline measurements; and (c) replicating experimental conditions (e.g., A-B-A-B) with each subject (Horner et al., 2005; Kratochwill et al., 2010; Pearce \& Cheney, 2017). Effect size estimations of SCDs were analyzed in a different project.

\section{Literature search and study selection process}

The search procedures for relevant records followed the recommendations of Petticrew and Roberts (2006) for conducting systematic literature reviews and meta-analyses and complied with the Preferred Reporting Items for Systematic Reviews and Meta-Analyses (PRISMA) guidelines (Liberati et al., 2009; Moher et al., 2009). A list of key search terms and phrases was systematically extracted from the full texts of ten relevant peer-reviewed papers. Due to their relevance, these records were automatically included in the final list of eligible studies. Only three out of the ten records were not retrieved during the systematic search of the databases (i.e., Butler, Sargisson \& Elliffe, 2011; Clark \& Boyer, 1993; Echterling-Savage et al., 2014).

Literature searches were conducted by utilizing following databases: Directory of European Research Theses (DART-Europe), Education Resources Information Center (ERIC), International Bibliography of the Social Sciences (IBSS), OpenGrey, PsychINFO, PubMed, ScienceDirect, Scopus, and Web of Science. 
No restrictions regarding publication dates were used. Inclusion criteria were: (a) studies constituted original research (i.e., peer-reviewed papers), conference proceedings, case studies or doctoral theses; (b) parents (i.e., the term "caregivers" is used from here on) were given advice and/or have implemented the behavioral treatments/interventions; (c) dog owners (i.e., the term "caregivers" is used from here on) were given advice and/or have implemented the behavioral treatment/interventions; (d) settings included home, clinical or any other external settings (e.g., therapy rooms, practices, dog training facilities or shelter environment); (e) caregivers were aged 18 years or older; (f) the study concerned advice and/or training given to caregivers on how to implement a behavior change program; (g) records involved either human or canine learners (e.g., Cottam et al., 2008; Najdowski et al., 2010); and (h) sources were published in English or German (i.e., first author's native language). The study selection process is summarized in Figure 1.

Forty-two of the relevant records had incomplete referencing information (i.e., either title, abstract or author information missing). These were evaluated during the second stage of the selection process (i.e., obtaining and screening of full texts for eligibility). For most of these articles (i.e., 36 records), full texts were obtained by exhausting following access options: (a) University's library resources (i.e., online catalogue function, contacting subject librarian, and requesting inter-library loan service); (b) searching Google ${ }^{\circledR}$ including Google ${ }^{\circledR}$ Scholar ${ }^{\mathrm{TM}}$; (c) searching online library systems of respective journals (e.g., Journal of the American Veterinary Medical Association or The Veterinary Record); (d) contacting respective authors. However, six of these 42 records had to be excluded due to inaccessibility of full texts, as neither of above strategies was successful in accessing respective records within the set time frame (i.e., November $30^{\text {th }} 2017$ to January $19^{\text {th }} 2018$ ).

To ensure reliability of relevance decisions, a trained research assistant (LGM) who was unaware regarding the aims of the study independently viewed $25 \%$ of the retrieved sources' abstracts based on the information provided by inclusion and exclusion criteria (i.e., 
"Screening" step - Figure 1). Studies appraised by the second reviewer were randomly selected utilizing the Microsoft巴 Excel application "random function” (i.e., assorting randomized numbers to each of the 856 total sources followed by randomly selecting 215 articles). Each reviewer's agreements and disagreements of the selected literature were compared, and an inter-rater agreement (i.e., IRA) score was calculated by number of agreements divided by number of agreements plus number of disagreements multiplied by 100. IRA computation yielded a 94\% agreement score across both reviewers. Any disagreements were resolved by discussion.

[Please insert Figure 1 here]

\section{Coding of studies and data extraction}

For the coding process, a specially designed Microsoft ${ }^{\circledR}$ Excel $^{\mathrm{TM}}$ matrix was utilized. All 66 studies were coded on following criteria: (a) reference information (i.e., title, authors, date, publication); (b) sample size; (c) description of selection of sample, i.e., demographic information and information whether human- or canine learners were participating; (d) description of undesired learner behavior; (e) methodological type (i.e., SCDs, group designs, case studies); (f) description of the intervention type; (g) procedural integrity of intervention implementation (if reported); (h) general, qualitative outcomes of experimental evaluation (i.e., positive, negative, mixed); and (i) effect sizes (e.g., Hedges' g for group designs). If effect sizes were not given in the original studies, they were computed by using data provided in the sources.

To ensure reliability of coding, a trained research assistant independently coded 17 out of 66 candidate studies (i.e., $>25 \%$ ). These articles were again randomly selected by utilizing the random function, a Microsoft ${ }^{\circledR}$ Excel $^{\mathrm{TM}}$ application. The Inter-coder agreement (ICA) score was determined by number of agreements divided by number of agreements plus number of disagreements multiplied by 100 . This computation was done for each of the 38 
variables (e.g., total population or learner undesired behavior) which yielded an ICA of 85\% across both coders. Disagreements were resolved by discussion.

\section{Meta-statistical analysis}

Out of 34 studies utilizing group designs, 18 studies reported suitable data for inclusion in a meta-analysis. Given there were at least three studies allowing a comparison, data were combined across studies focusing on type of interventions, e.g., oral instruction/advice or training package (i.e., a combination of two or more training components administered concurrently or consecutively; e.g., oral instruction/advice, modeling and feedback), and respective human or canine behavior change (i.e., outcome measures). If studies provided several measures for the same outcome, the primary outcome measure was selected based on the most complete information. Studies used different study designs (i.e., independent groups or repeated measures), and various measurement instruments (e.g., direct observation or standardized questionnaires) for assessing outcomes. For further analysis, measurements were therefore either aggregated to avoid dependence in the analysis (Borenstein, Hedges, Higgins \& Rothstein, 2009) or outcomes were selected based on relevance for the current research question. Three of the 18 included studies investigated either two or more intervention types (e.g., Saunders et al., [2013] used oral instruction/advice and modelling) or examined the effects of different interventions on various undesired behaviors (e.g., Clark \& Boyer, [1993] examined the effects of training in obedience and quality time interactions on separationrelated behaviors and other undesired behaviors).

Due to the across-studies differences, it was assumed that the true effect sizes varied from study to study, hence, it seemed reasonable to apply a random-effects model to the analysis (Borenstein, Hedges, Higgins \& Rothstein, 2015). Implementation of the randomeffects model allowed an analysis of the presence of moderators (Higgins \& Green, 2011). 


\section{Overall effect size}

The Comprehensive Meta-Analysis $\mathbb{C}$ software Version 3.0 (Biostat, 2018) was used to analyze data and compute standardized mean differences (SMD Hedges' g). The decision for reporting Hedges' g was reached because it introduces a correction factor for bias, yielding more accurate and conservative estimates when sample sizes are small (Borenstein et al., 2009). For the current analysis, Hedges' g estimates were weighted based on sample size and calculated with respect to the different study designs used. Lipsey \& Wilson (2001) stated that Hedges' $\mathrm{g}$ can be interpreted according to following guideline: small (0.20-0.49), medium (0.50-0.79), and large ( $\geq 0.80)$. However, such thresholds should always be interpreted contextually and with caution as numerically minor effects may have important impacts on participants' training or welfare. Follow-up and generalization measures were discarded, only selecting those measures for effect size estimation that were immediately involved with the treatment period. To summarize, the weighted mean effect size computations were calculated for all interventions across human-canine and human-human dyads, and separate analyses were conducted for training packages (PG) and oral instruction/advice (OI).

\section{Heterogeneity or between-study variation}

Computation of heterogeneity (i.e., $Q$ statistics, $T^{2}$ and $I^{2}$ ) of studies, as well as generating forest plots was conducted using the Comprehensive Meta-Analysis Software Version 3.0 (Biostat, 2018). The $Q$ test measured the presence of heterogeneity among studies and was computed as the weighted sum of squared differences between each study effects and the pooled effect across studies (Cochran, 1954). In other words, the $Q$ statistic gives information about whether included studies have unaccounted variance, and if specific characteristics are moderating the effect in addition to the assumption of random error (Germain et al., 2018). Further, if the $Q$ statistic yields a statistically significant $(p<0.05)$ result, the included studies do not share a common effect size (Borenstein et al., 2009), and that the between-study 
variation cannot be accounted for by sampling error (Littell, Corcoran \& Pillai, 2008).

Additional to $Q, T^{2}$ and $I^{2}$ statistics were calculated to further quantify heterogeneity. $T^{2}$ is an estimate of variance, which provides information about the variance of effect sizes across the population of studies (Borenstein et al., 2009; Borenstein, Hedges, Higgins \& Rothstein, 2010). $I^{2}$ on the other hand is a method to quantify the proportion of observed variation in the estimates of treatment effect that is due to heterogeneity between studies rather than chance and is expressed in percentage of total variability (Higgins \& Thomson, 2002; Neyeloff, Fuchs \& Moreira, 2012). A general guide to the interpretation of $I^{2}$ is as follows (Higgins \& Green, 2011): (a) $I^{2}$ values of $30 \%$ to $60 \%$ represent moderate heterogeneity; (b) $50 \%$ to $90 \%$ represent substantial heterogeneity; and (c) $I^{2}>75 \%$ represents considerable heterogeneity between study effects. However, $I^{2}$ should always be used and interpreted with caution and is best reported in combination with forest plots and $T^{2}$ to give the reader maximum information about heterogeneity and the true effects (Borenstein, n.d.).

\section{Moderator analysis}

The next step in the analysis was to investigate which study characteristics may have been associated with efficacy of interventions. This was achieved through the implementation of a moderator analysis. A meta-regression approach was used based on the type of characteristics available (e.g., type of study design and choice of comparison intervention - Higgins \& Green, 2011). Moderator analysis through meta-regression allowed the effect of continuous (e.g., publication year), as well as categorical (e.g., intervention type) features to be investigated, and principally also allowed the effects of multiple factors to be examined simultaneously (Higgins \& Green, 2011). The outcome variable was Hedges' $g$ and the characteristics extracted were the potential effect modifiers (Higgins \& Green, 2011; Keenan, 2018). 


\section{Publication bias}

The term publication bias refers to the issue that studies often report desirable outcomes (e.g., statistically significant results) more readily than nonsignificant outcomes (Petticrew \& Roberts, 2006). Obtaining and including published and unpublished studies irrespective of their results may at least partially address this issue (Higgins \& Green, 2011; Petticrew \& Roberts, 2006). Hence, the current review included grey-literature (e.g., reports produced by government agencies) databases, i.e., ERIC. Two unpublished doctoral dissertations (i.e., Mulford, 2011; Van Camp, 2005) were eligible for inclusion into the systematic review. However, both implemented SCDs and therefore were not included in the meta-analysis. A funnel plot was produced and visually assessed to detect potential publication bias. Funnel plots are scatterplots that outline each included study according to Hedges' g and standard error (Keenan, 2018). If the sample size of studies increased, the range of effect sizes estimated by each study decreased, which lead to more precise estimates. When such results are displayed as scatter plots, the latter show an inverted funnel shape (Petticrew \& Roberts, 2006). The funnel plot becomes asymmetrical and shows a gap in a bottom corner of the graph if a bias exists. The effect computed in a meta-analysis tends to overestimate the intervention effect. In other words, the more pronounced the asymmetry, the more likely that the level of bias is substantial (Higgins \& Green, 2011). However, if a meta-analysis consists of a representative number of studies with large sample sizes and statistically significant studies, which are more likely to be published, the funnel plot will appear symmetrical, indicting no publication bias, irrespective of selective publication based on p-values (Keenan, 2018). Since visual inspection of funnel plots is subjective, a linear regression between the standard error of included studies and their Hedges g's (i.e., Egger's regression - Egger et al., 1997) was computed. If the regression test yields statistical significance $(p<0.01)$, this result also indicates asymmetry in the funnel plot. Although Egger's regression is said to have increased power to detect bias (compared to a rank correlation), results should be carefully 
considered when moderate amounts of bias or meta-analyses based on small numbers of small studies are examined (Sterne, Gavaghan \& Egger 2000), as is the case in this study.

\section{Results}

The characteristics of the studies included in the meta-analytic review are displayed in Table 1.

[Please insert Table 1 here]

\section{Descriptive findings}

\section{Study characteristics}

Sources included in the current literature review were retrieved from several outlets, such as databases for accessing peer-reviewed papers and repositories storing grey literature. The systematic search yielded studies published between 1972 and 2017. Out of the 66 included studies, 96.9\% $(n=64)$ were peer-reviewed journal articles, while $3.0 \%(n=2)$ were unpublished doctoral dissertations from Universities in the USA. No other grey literature, such as book chapters, conference proceedings or government reports was eligible.

Most of the included articles were published in the Journal of Applied Behavior Analysis $(28.8 \%, \mathrm{n}=19)$, followed by the Journal of the American Veterinary Medical Association $(11 \%, \mathrm{n}=10)$, and the Journal of Child and Family Studies $(9 \%, \mathrm{n}=6)$. The remaining journals were somewhat similarly distributed across all sources, with Research in Autism Spectrum Disorders featuring 5\% (n=3) of studies, followed by Applied Animal Behavior Science, Behavioral Interventions, Journal of Applied Animal Welfare Science, Journal of Veterinary Behavior: Clinical Applications and Research, Prevention Science, and Veterinary Record featuring 3\% $(\mathrm{n}=2)$ of studies, each. The remaining journals, such as 
Australian Veterinary Journal, Behavior Therapy, Canadian Veterinary Journal, Clinical Case Studies, Education and Treatment of Children, Family Process, Focus on Autism and Other Developmental Disabilities, Journal of Autism and Developmental Disorders, Modern Veterinary Practice, Northwest Medicine, Pediatrics, Psychologie Francaise, Research in Developmental Disabilities, and Schweizer Archiv für Tierheilkunde all featured 2\% (n=1) of studies, respectively.

\section{Participant characteristics}

A considerable amount of variability regarding the details on participant characteristics was found across all studies. Noticeable, $21 \%(n=16)$ of all eligible studies $(n=66)$ did not clearly state their participants' or subjects' characteristics. Among the reported characteristics were details such as ethnicity and/or socio-economic status. However, coded variables relevant for the current review included caregiver population, caregiver education, caregiver gender, learner gender/sex, and learner age. Table 2 presents participant characteristics according to study designs and broken down to canine- or human-related studies.

Canine-related findings. Out of all canine studies $(n=28), 50 \%(n=14)$ of the papers did not clearly state characteristics of participants. Thirty-nine percent $(n=11)$ of the studies included female and male caregivers; $8 \%(n=2)$ of these studies also stated caregiver education, which were either low (secondary school; $n=1$ ) or medium (under graduate; $n=1$ ). Eleven percent $(n=3)$ of the papers consisted of female dog owners only and no level of education was provided.

Almost all canine studies $(93 \% ; \mathrm{n}=26)$ reported details about the dogs' age range and sex. Except for $7 \%(n=2)$ of the studies which did not clearly state this information. Many of the papers $(39 \% ; n=11)$ comprised puppies and adolescent dogs (i.e., 2 to 24 months). Eighteen percent ( $\mathrm{n}=5)$ of the studies had either adult dogs (i.e., 2 to 8 years) or 
mostly puppies and adolescent dogs as their subjects. Mostly adult dogs participated in 11\% $(n=3)$ of the papers. Only $7 \%(n=2)$ of the sources did not clearly state the age or age range of the subjects. Studies comprising senior dogs (i.e., older than 8 years) or mostly senior dogs were found in only $4 \%(n=1)$ of the sources, respectively.

A quarter of the included studies $(25 \% ; n=7)$ consisted of neutered male dogs as subjects, while almost as many papers $(21 \% ; n=6)$ did not clearly specify sex and neuter status of their subjects. The rest of the included studies $(54 \% ; n=15)$, involved either both sexes $(36 \% ; n=10)$ regardless of the neuter status or comprised of only female dogs $(18 \%$; $n=5)$, either neutered $(11 \% ; n=3)$ or $\operatorname{intact}(7 \% ; n=2)$.

Human-related findings. Information about the gender distribution was reported in $79 \%$ $(n=37)$ of studies. More than half $(57 \% ; n=27)$ of these had female caregivers (parents) participating only. In $21 \%(n=10)$ of the studies, parent gender distribution was not clearly specified. The rest of the included papers $(21 \% ; n=10)$ reported that male and female parents participated, with mostly females $(15 \% ; n=7)$, and both genders equally distributed in $6 \%$ $(n=3)$ of the studies.

Details about caregiver education was provided in $38 \%(n=18)$ of the studies. In $21 \%$ $(n=10)$ papers most participants had medium (i.e., undergraduate level) education, while in $17 \%(n=8)$ most participants had low-level (i.e., secondary school) education.

Eighty-three percent $(n=39)$ of all studies comprised children aged between one and eleven years of age. Younger children classified as infants (i.e., 0 to 1 year of age) participated in $9 \%(n=4)$ of papers. The rest of the included studies $(9 \% ; n=4)$ was almost equally distributed. Four percent $(n=2)$ of the studies did not clearly report the age of children, while adolescents (i.e., 12 to 18 years of age) and mostly children (i.e., 1 to 11 years of age) were found in $2 \%(\mathrm{n}=1$ each) of studies. 
The gender distribution of children was provided in $87 \%(n=41)$ of studies, while $13 \%$ $(n=6)$ did not report this information. In almost a third $(30 \%, n=14)$ of the papers, all participating children were males, while the rest of the studies $(57 \% ; n=27)$ comprised male and female children (i.e., mostly male, mostly female and both).

[Please insert Table 2 here]

\section{Intervention types and undesired behaviors}

Following sections provide detailed analyses of general type of study, type of interventions and learner undesired behaviors reported by canine or human research focus.

Canine-related studies. Twenty-nine (100\%) canine-related papers implemented three different types of research designs, i.e., case studies, group designs, and single case research designs distributed as $66 \%(\mathrm{n}=19), 28 \%(\mathrm{n}=8)$, and $(7 \%, \mathrm{n}=2)$ papers, respectively. Table 3 provides details.

A third $(66 \% ; n=19)$ of the papers utilized a case-study design. Of these, $31 \%(n=9)$ used oral instruction/advice only to inform dog owners on how to treat their dogs' undesired behaviors. The latter included stereotypic behaviors $(7 \% ; n=2)$, separation-related behaviors $(7 \% ; n=2)$; aggressive behavior $(7 \% ; n=2)$, fear and anxiety $(7 \% ; n=2)$, and one case study (3\%) simply stated behavior problems. Twenty-eight percent $(n=8)$ of the case studies used a combination of oral and written instruction/advice to enable dog owners to mitigate their dogs' fear and anxiety $(14 \% ; n=4)$, separation-related behaviors $(7 \% ; n=2)$, stereotypicbehavior $(3 \% ; n=1)$, and aggressive behavior $(3 \% ; n=1)$. One case study $(3 \%)$ used oral instruction/advice and modelling, while another one (3\%) implemented an intervention 
package to teach respective dog owners to train their dogs' hyperactivity and separationrelated behaviors, respectively.

Twenty-eight percent $(n=8)$ of canine-related studies implemented group designs. Out of these group studies, $7 \%(n=2)$ used a package to inform owners on the treatment of separation-related behaviors $(3 \% ; n=1)$ or fear and anxiety $(3 \% ; n=1)$. A combination of oral and written instruction/advice was used by $7 \%(\mathrm{n}=2)$ of respective studies to advice owners on treating separation-related behaviors $(7 \% ; n=2)$. Three percent $(n=1)$ of the papers instructed owners in obedience training and quality time to mitigate either separation-related behaviors $(3 \% ; n=1)$ or general behavior problems $(3 \%, n=1)$. Written instruction/advice only was used by one paper (3\%) to provide owners with information on how to train separationrelated behaviors $(3 \% ; n=1)$. Oral instruction/advice only was implemented by one paper (3\%) without clearly stating the undesired behaviors of participating dogs $(3 \% ; n=1)$.

SCDs were represented in the lowest count of studies. Only two papers or $7 \%$ used this type of research design and both papers implemented an intervention package to teach owners how to mitigate their dogs' separation-related behaviors $(3 \% ; n=1)$ or aggressive behaviors $(3 \% ; n=1)$.

[Please insert Table 3 here]

Human-related findings. Out of all $46(100 \%)$ human-related studies, 57\% $(\mathrm{n}=26)$

implemented SCDs, 39\% $(n=18)$ utilized group designs, while only $4 \%(n=2)$ were designed as case studies. Table 4 displays this information.

Across the single SCDs, a large variation of caregiver (parent) training strategies was found. Most of these papers used an intervention package $(37 \% ; n=17)$ for training caregivers to treat undesired behaviors of children. Out of the studies that implemented a package, $7 \%$ $(n=3)$ dealt either with undesired behaviors during mealtimes or language delays. Four 
percent $(n=2)$ of the studies utilizing a package taught parents to intervene with either behavior problems of some sort, non-compliance and oppositional behavior, language/communication and motor skill deficits, or did not clearly state the target behavior. Oppositional behavior, behavioral deficits, and autism spectrum disorder and language delays were found in only $2 \%(\mathrm{n}=1)$ of the papers utilizing a package approach. The rest of the SCD parent-training interventions $(14 \%, \mathrm{n}=7)$ mainly consisted of combinations of two or more approaches (e.g., written instruction/advice, video modelling, feedback and modelling), designed to treat a range of undesired behaviors, such as deficits in language, social interactions and academic skills distributed with $2 \%(n=1)$ within each intervention type. Two studies $(2 \% ; n=1)$ did not report the undesired behaviors displayed by respective children.

Group designs followed single SCDs by contributing 39\% $(n=18)$ of papers to all eligible records. Again, intervention packages comprised the majority of group design studies $(35 \% ; n=16)$. Thirteen percent $(n=16)$ of these studies did not clearly state the type of undesired behavior, $7 \%(\mathrm{n}=3)$ of the papers just generally stated behavior problems. However, $4 \%(n=2)$ of studies reported the undesired behaviors as either being related to autism spectrum disorder and language delays or oppositional behavior. One study $(2 \%)$ each dealt with inattentive and hyperactive symptoms, deficits in language, social interaction and academic skills, and fear and anxiety. The rest of the group-design records consisted of studies using a combination of caregiver-training approaches, i.e., oral instruction/advice plus modelling $(2 \% ; n=1)$ or package plus written instruction/advice plus oral instruction/advice $(2 \% ; n=1)$. Both studies did not report the target behaviors of their interventions.

Only 4\% $(n=2)$ of human-related papers were case studies and both implemented combinations of various caregiver-training approaches. One case study dealt with behavioral deficits by teaching parents using oral instruction/advice plus modelling plus feedback. The second case study implemented an intervention package but unfortunately did not further state the type of undesired behavior the treatment was designed for. 
[Please insert Table 4 here]

\section{Qualitative caregiver-training outcomes}

Across all designs, qualitative findings of caregiver training could be either "positive" (i.e., clear improvement in caregiver behavior after training), "mixed" (i.e., improvements were reported for some caregivers but was not seen in all), "negative" (i.e., decline in caregiver behavior was detected) or "not clearly stated" as indicated by the authors of eligible studies. Following sections report respective data in more detail.

Canine-related findings. Of the eligible case studies $(66 \% ; n=19)$, the majority $(45 \% ; n=13)$ did not clearly report the outcomes of the caregiver intervention. Oral instruction only, a combination of oral plus written instruction/advice, and a training package were used in $24 \%$ $(n=7), 17 \%(n=5)$, and $3 \%(n=1)$ of the cases, respectively.

Most of the group designs $(21 \% ; n=6)$ did not clearly state the outcome of the training intervention, while two studies reported mixed $(3 \% ; n=1)$ or positive $(3 \% ; n=1)$ outcomes. The interventions used were either a package $(7 \% ; n=2)$, oral plus written instruction/advice $(7 \% ; n=2)$ or instructed the owners on obedience training or quality time $(3 \% ; n=1)$.

Seven percent $(\mathrm{n}=2)$ of the studies were SCDs implementing an intervention package, either resulting in a positive outcome or not clearly stating it $(3 \% ; \mathrm{n}=1$ each). Table 5 displays these findings in detail.

[Please insert Table 5 here]

Human-related findings. Forty-six percent $(\mathrm{n}=21)$ of SCDs showed positive caregiver-training outcomes. Of those positive-outcome studies, 30\% $(n=14)$ implemented an intervention package, while the rest of the caregiver training strategies were found only once $(2 \% ; n=1)$ among each of the studies (Table 6). 
Four percent of the studies $(\mathrm{n}=2)$ did not clearly state the outcomes, and distribution of written instruction/advice and intervention package was $2 \%(n=1)$, respectively.

Among the group designs $(39 \% ; n=18), 28 \%(n=13)$ showed positive outcomes, with $24 \%(n=11)$ using an intervention package, while oral instruction/advice plus modelling and package plus written instruction/advice plus oral instruction/advice were implemented in only $2 \%(\mathrm{n}=1)$ of the studies.

Both case studies (4\%) resulted in positive caregiver-training outcomes, with one implementing oral instruction/advice plus modelling plus feedback, and the second one using an intervention package.

Table 6 displays these findings in detail.

[Please insert Table 6 here]

\section{Learner outcomes}

Unlike above section about caregiver training outcome, this section is concerned with the intervention outcomes for respective learners. This means that learner behavior change was qualitatively coded as either increase desired behavior, decrease undesired behavior, increase undesired behavior, decrease desired behavior or mixed, depending on how study authors reported their findings. Learner outcomes were analyzed according to type of research design and type of interventions which were used to teach behavior change strategies to caregivers.

Canine-related findings. Table 7 displays learner outcomes of all included canine-related studies. Case studies represented the majority of study designs $(66 \%, n=19)$, with $31 \%(n=9)$ of them reporting a decrease of learner undesired behaviors when utilizing either oral instruction/advice only $(21 \% ; n=6)$, oral plus written instruction/advice $(7 \% ; n=2)$, and oral instruction/advice plus modelling ( $3 \% ; n=1)$. Mixed learner outcomes were found in $24 \%$ $(n=7)$ of the case studies. Latter implemented either oral plus written instruction/advice $(17 \%$; 
$\mathrm{n}=5)$ or oral instruction/advice only $(7 \% ; \mathrm{n}=2)$. An increase in the dogs' desired behavior was found in $10 \%(n=3)$ of the case studies. Three percent $(n=1)$ used either oral instruction/advice only, oral plus written instruction/advice or an intervention package.

Out of $28 \%(n=8)$ group design studies, the majority $(21 \%$; $n=6)$ reported a decrease in the dogs' undesired behaviors. Seven percent $(n=2)$ of these studies used intervention packages or instructed owners in obedience training plus quality time, respectively. Seven percent $(\mathrm{n}=2)$ of group design that used either oral plus written instruction/advice $(3 \%$; $\mathrm{n}=1$ ) or oral instruction/advice only yielded mixed learner outcomes.

Both SCDs (7\%) implemented intervention packages to train participating dog owners and both reported a decrease in undesired canine behavior.

[Please insert Table 7 here]

Human-related findings. Within the large group of SCDs $(57 \% ; \mathrm{n}=26)$, all coded learner outcomes could be found. An increase in desired learner behavior was detected in $22 \%(n=10)$ of the studies, with intervention package, a combination of modelling plus package, and oral instruction/advice plus package distributed with $17 \%(\mathrm{n}=8), 2 \%(\mathrm{n}=1)$, and $2 \%(\mathrm{n}=1)$, respectively. Fifteen percent $(n=7)$ of SCDs resulted in a decrease of undesired learner behavior when parents were trained utilizing either an intervention package $(9 \%, n=4)$, a combination of written instruction/advice plus video modelling plus feedback plus modelling $(2 \% ; n=1)$, feedback only $(2 \% ; n=1)$, or written instruction/advice only $(2 \% ; n=1)$. Mixed learner outcomes were found in three studies (7\%), of which two (4\%) implemented an intervention package, while the other one $(2 \%)$ combined a package plus feedback to train parents. The last outcome variable coded within SCDs is increase of undesired behavior, which was reported in only one study $(2 \%)$, which also used an intervention package.

The majority of group designs did not clearly state the learner outcome $(15 \% ; n=7)$. Of those inconclusive outcomes, $11 \%(n=5)$ implemented an intervention package to teach 
parents how to mitigate undesired behaviors of their children, $2 \%(n=1)$ used a combination of oral instruction/advice plus modelling, and another $2 \%(\mathrm{n}=1)$ implemented a package plus written instruction/advice plus oral instruction/advice. Thirteen percent $(n=6)$ of group design studies reported a decrease in learner undesired behavior and all of them used an intervention package $(13 \% ; n=6)$. The latter was also utilized in $7 \%(n=3)$ of studies that reported an increase in desired learner behaviors, and in $4 \%(n=2)$ of studies that found mixed learner outcomes.

Out of the two case studies (4\%), one did not clearly state the outcome for respective learner when utilizing an intervention package for caregiver training. The second case study reported an increase in learner desired behavior when using a combination of oral instruction/advice plus modelling plus feedback. Table 8 shows learner outcomes of all included human-related studies.

[Please insert Table 8 here]

\section{Meta-statistical findings}

Only group designs were considered for quantitative analysis. Eighteen out of 34 studies reported suitable data to be included in effect size calculations (included studies are highlighted in bold in Table 1), five of which were canine-related studies. Sixteen studies did not provide sufficient data for the meta-analysis.

\section{Meta-analysis results}

Six types of interventions (i.e., package, oral instruction/advice, written instruction/advice, modelling, quality time, and instruction in obedience) were used to assess the behavior change outcomes of caregivers and their respective learners. However, only package $(n=12)$ and oral instruction/advice $(\mathrm{n}=4)$ were used in more than three studies. Thus, here we only 
analyze findings on package and oral instruction/advice and offer a summary of all effect size computations across interventions (Figures 2 to 5).

Most of the studies ( $\mathrm{n}=12)$ implemented training packages (Figure 2$)$ demonstrating a medium summary effect size (Hedges' $\mathrm{g}=0.76,95 \% \mathrm{CI}[0.60-0.91], \mathrm{p}=0.00$ ).

[Please insert Figure 2 here]

About a quarter of the studies $(n=4)$ applied oral instruction/advice only which also yielded a medium summary effect size (Hedges' $\mathrm{g}=0.74,95 \% \mathrm{CI}[0.32-1,15], \mathrm{p}=0.00$; Figure 3). Although both intervention types emerged with a moderate summary effect size (i.e., 0.500.79), the implementation of packages resulted in a slightly larger effect than using oral instruction/advice only (i.e., Hedges g’s 0.76 vs. 0.74).

[Please insert Figure 3 here]

When examining effect sizes across all studies (Figure 4), more than half of them $(n=10)$ showed intervention effects of Hedges' $\mathrm{g}>1.0$ (range 1.03-1.76). The summary effect size across all studies and intervention types was $0.88(95 \%$ CI $[0.68-1.07, p=0.00)$ pointing to an overall large effect of examined studies and respective interventions.

[Please insert Figure 4 here]

\section{Assessment of heterogeneity}

After testing for heterogeneity among the 18 studies, results suggest that variability was larger than could be explained by sampling error $\left(Q=114.76[d f=17], p<0.001, T^{2}=0.13\right)$. In other words, this means that the included studies do not share a common effect size. As an additional measure which gives a proportion of heterogeneity, $I^{2}$ was calculated $\left(I^{2}=85 \%\right)$. A 
generally accepted guideline is that an $I^{2}$ of $>75 \%$ means considerable variance between study effects (Higgins \& Green, 2011).

\section{Moderator analysis}

Although the number of studies was small $(n=18)$, which is thought to be a limitation factor for conducting these statistical analyses (Borenstein et al., 2009), meta-regressions were computed for all interventions and for variables that seemed associated with efficacy (i.e., study design, learner species and age, year of publication, and study duration). Out of these six variables four yielded statistically significant results (Table 9).

The variable learner species had a statistically significant effect on the studies' efficacy $(p<0,05)$, namely, those studies having companion dogs as learners showed a larger effect than studies involving human learners (Figure 5a). Similarly, the variable learner age was also statistically significantly associated with larger effect sizes of studies involving adolescent and adult dogs ( $p<0.05$; Figure 5b). Figure 5c displays a regression line, which was thought to better report respective data. While the number of studies importantly increased from 2005 onwards, efficacy of studies significantly decreased with progression of time ( $p<0.05$; Figure $5 \mathrm{c})$. Duration of the training interventions was also statistically significantly influencing effectiveness ( $p<0.05$; Figure $5 \mathrm{~d}$ ). Results showed that interventions of longer duration (i.e., larger six months) were less effective than treatments that lasted between three and six months.

[Please insert Table 9 here]

[Please insert Figure 5 here]

\section{Publication bias}


A funnel plot was generated to visually analyze the presence of publication bias among the included studies (Figure 6). The funnel plot appeared asymmetrical, which indicated the presence of publication bias. To test this assumption, a linear regression between the standard error of the included studies and the Hedges' g (i.e., Eggers regression; Egger et al., 1997) was conducted. Egger's regression method (Egger et al., 1997) yielded a statistically significant $(p<0.01)$ result, confirming the presence of publication bias and other small-study effects.

[Please insert Figure 6 here]

\section{Discussion}

While the effectiveness of caregiver training was repeatedly shown in educational, psychological, and behavior-analytic research, including meta-analyses (e.g., Bearss, Burrell, Stewart \& Scahill 2015; Crone \& Mehta, 2016; Fukkink \& Lont, 2007; Ilg et al., 2018), the topic did not yet attract wide attention within the animal behavior research community (Coe et al., 2014; Howard \& DiGennaro-Reed, 2014). This is surprising as similarities between owner-dog and parent-child relationships (Hare \& Tomasello, 2005; Prato-Previde et al., 2003; Prato-Previde \& Valsecchi, 2014; Tomasello \& Kaminski, 2009; Topal, Miklósi, Csányi \& Dóka, 1998; van Herwijnen et al., 2018) are well-established, and many sources rely on dog owners to follow the animal behaviorists' instructions to implement the interventions accordingly (e.g., Butler et al., 2011; Echterling-Savage et al., 2014). In this vein, previous studies suggested that training caregivers to implement interventions with integrity may benefit treatment outcomes (e.g., Belfiore et al., 2008; Fryling et al., 2012). Therefore, this review aimed at examining the current situation of the literature from an interdisciplinary perspective across species. 


\section{Systematic review}

This review found that human-related studies were mostly located within SCDs, while caninerelated studies were mainly found as case studies. The latter was also remarked by Butler et al. (2011), which hints to the need for individual assessment and treatment of unwanted canine behaviors by practitioners. Case studies and SCDs emphasize this individuality of treatments of canine behavior problems, however, case studies lack the systematic and datadriven approach of SCDs. The second most used designs across species were group designs. One reason why only few group designs were found among eligible canine-related studies may lie in their feasibility with behavioral interventions. For instance, to achieve a strong research design, untreated control groups or other comparison groups (i.e., "treatment as usual") are implemented. This practice, however, may lead to ethical implications due to withholding potentially much needed treatment for participants (Kimmel, 2007).

Among the different study designs and across species, following teaching approaches were found: (a) packages (i.e., concurrent or consecutive implementation of two or more interventions); (b) oral instruction/advice; (c) written instruction/advice; (d) modelling; (e) feedback; (f) video modelling; (g) instructions in obedience training; (h) quality time; and (i) modelling plus role play.

Out of all interventions, packages were the most widely used approaches for humanrelated studies, while canine-related studies more frequently implemented oral instruction/advice. Packages comprised any of the identified interventions above but could also include otherwise unidentified components, i.e., reading assignments or counterconditioning. For the human-related SCDs and group designs, packages yielded mostly positive outcomes for caregiver and learner behavior change, however, packages were also found in studies with mixed and not clearly stated outcomes. The situation for caninerelated studies was shown to be different. Packages were mostly found in not clearly stated classifications of case studies, group designs and SCDs for both caregiver and learner 
outcomes. The latter may be linked to the systematic approach of SCDs on caregiver training which underscores the need for testing the suitability efficacy of various teaching strategies (i.e., modelling and/or feedback) with dog owners.

The finding that most canine-related interventions comprised oral instruction/advice only yielding inconclusive caregiver and learner outcomes may further the notion that oral instruction/advice is not sufficient to teach owners the necessary skills to train their dogs. This suggestion may be further backed up by the finding that parent-training packages yielded almost consistently positive outcomes. The meta-analysis attempted to test these expectations.

\section{Meta-analysis}

The current meta-analysis investigated the effectiveness of studies using group designs only. The decision to focus on group designs was reached because SMDs have a longer tradition and are therefore more readily computable and interpretable (Hedges, Pustejovsky \& Shadish, 2012).

Overall, Summary effects showed that training caregivers was effective in changing the undesired behaviors of learners, irrespective of the learner's species.

Both packages and oral instruction/advice produced similar moderate effects. Although interventions classified as packages yielded a slightly larger effect, not all packages were equally effective. Differences between measures used to assess outcomes may have contributed to wide-ranging effect sizes (e.g., Hedges g's ranged from 0.189 to 3.120 across outcome measures - Pelham, Schnedler, Bologna \& Contreras, 1980). Some studies yielded close to null effects, while one study even showed a negative effect (i.e., the intervention had undesired effects). Two distinct notions may at least partially explain these findings. First, considering methodological characteristics of the studies, the testing instruments (i.e., measures) may have been too crude or too remote from the interventions to reliably assess training effects. This may be especially true for studies that heavily relied on questionnaires 
for outcome evaluation. Questionnaires are known to involve a degree of subjectivity and hence are prone to biases (Choi \& Pak, 2005; Duffy, Hsu \& Serpell, 2008) which may have contributed to some of the effect size outliers on both sides. While including studies into the review that used questionnaires does not constitute a problem, Petticrew \& Roberts (2006) recommend avoiding questionnaires that have not previously been useful in similar reviews. Therefore, such studies were included in the current analysis as excluding these types of sources may have introduced bias into the findings, as it is practically impossible to eliminate all biases using survey methods (Nederhof, 1985). Additionally, studies that implemented packages generally mentioned the components in their method sections but reported the findings as overall treatment outcomes without investigating and specifying which components of the intervention package may have been the most effective ones. This lack of information could also have contributed to the variation in effect sizes (Bear \& Nietzel, 1991). Second, conceptual explanations for these findings should also be considered. To the authors' knowledge this is the first time that a comparison of the effectiveness of caninerelated and human-related training interventions has been attempted. Hence, it is important to underscore the commonalities of the possible communicative processes involved as dogs and humans evolved together and formed a special relationship (Prato-Previde, 2014). However, just like humans, dogs can also develop problematic behaviors. In such cases, dog owners often seek the help of certified animal behaviorists who typically develop individually tailored interventions. The latter are based on similar conceptual frameworks and techniques (e.g., reinforcement and shaping) as for human learners (Gray \& Diller, 2017). Whether the necessary techniques and information are conveyed to the owner by oral or written instructions, feedback (i.e., descriptions of performance that may increase one aspect of the caregivers behavior, while decreasing another - Cooper, Heron \& Heward, 2007), demonstrations (i.e., modelling), classes owners must attend, or a combination of these (i.e., 
package), lies mostly in the responsibility and skill set of the behaviorist and depends on the respective context in which the undesired behavior occurs.

All these approaches have in common the key assumption that rule-following will occur. The latter is defined as the effect of contingency-specifying discriminative stimuli (i.e., rules) on the listener's behavior. These stimuli could take the form of spoken, written and/or gestural instructions, rules, advice, maxims, and/or laws that signal reinforcement relations (Baum, 2017; Catania, Shimoff \& Matthews, 1989; Skinner, 1984). For instance, an animal behaviorist provides following oral or written instruction (i.e., a rule) to the caregiver: "as soon as you enter the room and your dog has four paws on the floor you should deliver attention in form of praise and petting for about 20s." When these rule-type stimuli regulate operant behavior, the behavior is said to be rule governed, or that rule-following behavior has occurred (Baum, 2017; Pierce \& Cheney, 2017). Occurrence and maintenance of rulefollowing behavior is explained functionally, i.e., that is, in terms of reinforcement relations (e.g., tracking - Hayes, Zettle \& Rosenfarb, 1989). A rule describes that behaving in a specific way will produce reinforcement. If the actual occurrence of such prescribed behavior indeed produces the predicted reinforcement, the rule becomes an effective form of advice or instruction, and thus the related rule-following behavior increases the probability of reoccurring in the future (Skinner, 1984). In the previous example, if the dog owner behaves in the way the animal behaviorist's instruction stated and, as a result of that, the dog behaves more appropriately, the owner's rule-following behavior will be reinforced (i.e., the owner will keep doing what was instructed).

This example illustrates ultimate (i.e., long-term) relations of rule-following and respective reinforcement (i.e., the temporal gap between the moment in which the instruction is provided, the performance of the dog owner, and the occurrence of appropriate behavior of the dog that reinforces the rule following). However, it is well known that delay of reinforcement and ill-defined relations (e.g., imprecise or incomplete rules) are typically less 
effective regulating behavior (Baum, 2017), which often leads to cessation of rule-following (i.e., "non-compliance"). Hence, more proximate reinforcement of rule-following is typically necessary, for that behavior to reoccur (Baum, 2017). Such proximate reinforcers are usually delivered by the behaviorist in the form of praise (e.g., "well done") in the context of the caregiver reproducing/simulating the instructed behavior. This in turn increases the probability of future occurrences of similar behavior in similar settings (e.g., when the dog owner attempts to train the dog on his own on a different scenario), and thus the natural reinforcement of rule following (i.e., producing the reinforcing consequence that the rule specifies; e.g., that the dog behaves in the desired manner).

This rule-following conceptual analysis, coupled with the fact that modelling and feedback involve immediate differential reinforcement of successive approximations to the target behavior of the caregiver during training (i.e., shaping - Cooper et al., 2007), allowed us to predict that packages, modelling and feedback would have produced larger effects than solely oral or written instructions. This especially considering that the latter two interventions may produce only delayed reinforcement, if any at all. Although the fact that packages and oral instruction/advice both yielded similar moderate effects, which did not support our predictions, it should be noted that a detailed analysis of modelling, feedback, quality time and obedience instructions could not be conducted due to a very small number of studies, i.e., one or two for each intervention. Nevertheless, it seems plausible that the advantage of training packages may lie in the fact that they involve various approaches, some of them increasing aspects of caregiver performance, while others decrease different ones (e.g., constructive feedback). Though further research is clearly needed, it appears that effective and reliable interventions based on rule-following require that this behavior contacts reinforcement via the behaviorist and/or the natural setting. If this is not the case, effectiveness of individual components may decrease, and compliance of owners ultimately may break down. 
After conducting the meta-regression, learner species was shown to have an influence on effectiveness of interventions with canine-related interventions being more effective than human-related ones (see Figure 5a). A possible reason for this finding may be that a small number of canine-related studies and the pre-test/post-test designs included in this subgroup artificially enlarged effect size estimates due to instrumental bias, maturation and/or order effects (Gravetter \& Forzano, 2018). In general, learners seemed to be of younger age (i.e., puppies and adolescent dogs, adult dogs and children between one and eleven years), a finding that was also seen to influence effectiveness of interventions. These results are in line with existing literature which points to the notion that younger dogs may be more likely to engage in undesired behaviors, e.g., separation-related behaviors, and that among certain caregiver populations if dogs are acquired as puppies risks may be higher that the dogs are being relinquished at a later point (Blackwell et al., 2008; Weng et al., 2006). The fact that mostly younger learners were included in the studies may also hint to a "catch 'em early"approach, i.e., that behavioral interventions are most effective when implemented at an early age (i.e., as soon as possible after diagnosis) and intensively (i.e., at least $20 \mathrm{~h}$ per week Reichow, 2012; Rivard et al., 2017) in young human learners, for instance.

Meta-regression of year of publication (Figure 5c) shows that number of research output increased from the year 2005 onwards, and that overall effectiveness of studies decreased with progression of time. Simultaneously, CIs became notably narrower. The actual impact of the intervention likely falls somewhere in the range of the CI for any given effect size estimate (Borenstein et al., 2009). These findings may hint to the notion that studies became more accurate over time, and that decreasing effectiveness may be a result of increased research output (Nelson, Wooditch \& Dario, 2014). Another moderating variable was study duration. This analysis found that caregiver training and respective interventions were most effective when between three and six months long. This is in line with an earlier meta-analysis that also investigated the effectiveness of caregiver training (i.e., teachers). 
Fukkink \& Lont (2007) reported that the average duration of their investigated interventions was six months, potential moderating properties of study duration were not assessed, however.

\section{Limitations}

This meta-analytic review has several limitations. First, the applied search strategy led to high sensitivity (i.e., proportion of all studies retrieved by the search) but at the same time yielded low specificity (i.e., proportion of retrieved studies that were relevant) which resulted in relevant studies being hidden among many irrelevant sources (Petticrew \& Roberts, 2006). Second, due to resource constrains, a quality assessment of eligible studies, such as the guidelines by the Grading of Recommendations Assessment, Development and Evaluation (GRADE) Working Group (Guyatt et al., 2011) for group designs, What Works Clearinghouse Single-Case Design Technical Documentation (Kratochwill et al., 2010) for SCDs, and Guidelines for Clinical Case Reports in Behavioral Clinical Psychology (ViruesOrtega \& Moreno-Rodriguez, 2008) for case studies could not be conducted. Finally, a more detailed analysis of the training methods entailed in packages required that these components should have been extracted during the coding stage of the present study. Where possible, such approach would have permitted a comparison of treatment-package components with respective studies' effect size estimates.

\section{Conclusions and future directions}

This meta-analytic review found that (a) most canine-related papers were case studies, pointing to a lack of intervention research implementing other more robust methodologies (i.e., SCDs or group designs); (b) overall, interventions had a large effect on training outcomes across species; (c) intervention packages, as well as oral instruction/advice were moderately effective in behavior change outcomes for caregivers and learners; and (d) 
interventions were most effective when between three and six months in duration irrespective of the learner species. Especially the latter two points are considered to have practical importance for a wide array of caregivers, such as dog owners, animal behaviorists and shelter staff.

Overall, more systematic and comparative research regarding the roles of caregivers in behavior change programs across species is needed. The field of human behavior change can inform canine-related research on how to more effectively teach owners how to train their dogs to help keeping them in their families and potentially reducing the number of dogs being relinquished to shelters due to behavior problems. Future primary research hopefully states in more detail which parts of the intervention were conducted by caregivers and report data on those procedures and respective integrity. Additionally, researchers should clearly state when they use a treatment package, describe its components and report results according to the components used. 8600 words 


\section{Acknowledgements}

The authors thank the researchers and librarians who readily shared their work and helped in retrieving relevant sources.

\section{Disclosure statement}

The authors report no conflict of interest.

\section{Funding}

This project did not receive any funding. 


\section{References}

Eligible studies as detailed in Table 1 are indicated by an asterisk $(*)$.

Baum, W.M. (2017). Understanding Behaviorism: Behavior, Culture, and Evolution ( ${ }^{\text {rd }}$ ed.). Chichester, UK: John Wiley \& Sons, Inc.

Bear, R.A., \& Nietzel, M.T. (1991). Cognitive and behavioral treatment of impulsivity in children: a meta-analytic review of the outcome literature. Journal of Clinical Child Psychology, 20(4), 400-412. DOI: http://dx.doi.org/10.1207/s15374424jccp2004_9

Bearss, K., Burrell, T.L., Stewart, L., \& Scahill, L. (2015). Parent Training in Autism Spectrum Disorder: what's in a name? Clinical Child and Family Psychology Review, 18(2), 170-182. DOI: 10.1007/s10567-015-0179-5

Belfiore, P.J., Fritts, K.M., Herman, B.C. (2008) The role of procedural integrity - using selfmonitoring to enhance Discrete Trial Instruction (DTI). Focus on Autism and Other Developmental Disabilities, 23(2), 95-102. DOI: 10.1177/1088357607311445

*Ben-Chaabane, D.B., Alber-Morgan, S.R., \& DeBar, R.M. (2009). The Effects of ParentImplemented PECS Training on Improvisation of Mands by Children with Autism. Journal of Applied Behavior Analysis, 42(3), 671-677. DOI: 10.1901/jaba.2009.42-671

*Bennett, S.L. (2013). Animal Behavior Case of the Month. Journal of the American Veterinary Medical Association, 243(12), 1697-1699.

*Berger, J. (2009). Animal Behavior Case of the Month. Journal of the American Veterinary Medical Association, 234(3), 332-334.

*Berger, U. (1999). Case report from veterinary behaviour medicine [Fallvorstellung Verhaltensmedizin]. Schweizer Archiv für Tierheilkunde, 141(7), 325-329. DOI: $10.5169 /$ seals-591901

Biostat, Inc. (2018). The Comprehensive Meta-Analysis $\subset$ (Version 3.0) [Computer software]. Englewood, NJ, USA: Biostat, Inc. Retrieved from https://www.metaanalysis.com/index.php?cart=BMNJ1648138

*Blackwell, E., Casey, R.A., \& Bradshaw, J.W.S. (2006). Controlled trial of behavioural therapy for separation-related disorders in dogs. Veterinary Record, 158(16), 551-554.

*Blackwell, E.J., Casey, R.A., \& Bradshaw, J.W.S (2016). Efficacy of written behavioral advice for separation-related behavior problems in dogs newly adopted from a rehoming center. Journal of Veterinary Behavior: Clinical Applications and Research, 12, 13-19. DOI: $10.1016 /$ j.jveb.2016.01.001

Blackwell, E.J., Twells, C., Seawright, A., \& Casey, R.A. (2008). The relationship between training methods and the occurrence of behavior problems, as reported by owners, in a population of domestic dogs. Journal of Veterinary Behavior: Clinical Applications and Research, 3, 207-217. DOI: 10.1016/j.jveb.2007.10.008 
Blampied, N.M. (1999). A legacy neglected: restating the case for single-case research in cognitive-behaviour therapy. Behaviour Change, 16(2), 89-104. DOI:

http://dx.doi.org/10.1375/bech.16.2.89

Borenstein, M. (2009). Effect sizes for continuous data. In H. Cooper, L.V. Hedges \& J.C. Valentine (Eds.), The Handbook of Research Synthesis and Meta-Analysis (pp. 221-235). New York, NY, USA: Russel Sage Foundation.

Borenstein, M., Hedges, L.V., Higgins, J.P.T., \& Rothstein, H.R. (2009). Introduction to Meta-Analysis. Chichester, UK: John Wiley \& Sons, Ltd.

Borenstein, M., Hedges, L.V., Higgins, J.P.T., \& Rothstein, H.R. (2010). A basic introduction to fixed-effect and random-effects models for meta-analysis. Research Synthesis Methods, 1, 97-111. DOI: $10.1002 / \mathrm{jrsm} .12$

Borenstein, M., Hedges, L.V., Higgins, J.P.T., \& Rothstein, H. (2015). Regression in MetaAnalysis. Retrieved from https://www.meta-analysis.com/downloads/MRManual.pdf Accessed June 102018

Borenstein, M., Higgins, J.P.T., Rothstein, H.R., \& Hedges, L.V. (n.d.). $\mathrm{I}^{2}$ is not an absolute measure of heterogeneity in a meta-analysis. Retrieved from https://www.meta-analysisworkshops.com/pages/paperseries.php Accessed June 122018

*Brody, G.H., McBride M.V., Chen, Y., Kogen, S.M., \& Brown, A.C. (2006). Effects of Family Risk Factors on Dosage and Efficacy of a Family-centered Preventive Intervention for Rural African Americans. Prevention Science, 7(3), 281-291. DOI: 10.1007/s11121006-0032-7

*Butler, R., Sargisson, R.J., \& Elliffe, D. (2011). The efficacy of systematic desensitization for treating the separation-related problem behaviour of domestic dogs. Applied Animal Behaviour Science, 129, 136-145. DOI: 10.1016/j.applanim.2010.11.001

*Buzhardt, J., Rusinko, L., Heitzman-Powell, L., Trevino-Maack, S., \& McGrath, A. (2016). Exploratory evaluation and initial adaptation of a parent training program for Hispanic families of children with autism. Family Process, 55(1), 107-122. DOI: 10.1111/famp. 12146

*Camp, C.M.V. (2005) Behavior analysis in child welfare: A preliminary program evaluation. Lousiana State University and Agricultural and Mechanical College, LSU Doctoral Dissertation.

Catania, A.C., Shimoff, E., \& Matthews, B.A. (1989). An Experimental Analysis of RuleGoverned Behavior. In S.C. Hayes (Ed.), Rule-Governed Behavior: Cognition, Contingencies, and Instructional Control. New York, NY, USA: Plenum Press.

Choi, B.C.K., \& Pak, A.W.P. (2005). A catalog of biases in questionnaires. Preventing Chronic Disease, 2(1), A3. Retrieved from https://www.ncbi.nlm.nih.gov/pmc/articles/PMC1323316/ Accessed June 272018 
*Clark, G.I. \& Boyer, W.N. (1993). The effects of dog obedience training and behavioural counselling upon the human-canine relationship. Applied Animal Behaviour Science, 37, 147-159. DOI: 10.1016/0168-1591(93)90107-Z

Clutton-Brock, J. (1995). Origins of The Dog: Domestication and Early History. In J. Serpell (Ed.), The Domestic Dog: Its Evolution, Behavior and Interactions with People. Cambridge, UK, Cambridge University Press.

Cochran, W.G. (1954). The combination of estimates from different experiments. Biometrics, 10(1), 101-129. DOI: $10.2307 / 3001666$

Coe, J.B., Young, I., Lambert, K., Dysart, L., Nogueira-Borden, L., \& Rajic, A. (2014). A scoping review of published research on the relinquishment of companion animals. Journal of Applied Animal Welfare Science, 17(3), 253-273. DOI: 10.1080/10888705.2014.899910

Cooper, J.O., Heron, T.E., \& Heward, W.L. (2007). Applied Behavior Analysis (2 ${ }^{\text {nd }}$ ed.). Upper Saddle River, NJ, USA, Prentice Hall.

*Cottam, N., Dodman, N.H., Moon-Fanelli, A.A., \& Patronek, G.J. (2008). Comparison of remote versus in-person behavioral consultation for treatment of canine separation anxiety. Journal of Applied Animal Welfare Science, 11(1), 28-41. DOI: 10.1080/10888700701729148

*Crockett, J.L., Fleming, R.K., Doepke, K.J., \& Stevens, J.S. (2005). Parent training: Acquisition and generalization of discrete trials teaching skills with parents of children with autism. Research in Developmental Disabilities, 28(1), 23-36. DOI: 10.1016/j.ridd.2005.10.003

*Crone, R.M. \& Mehta, S.S. (2016). Parent training on generalized use of behavior analytic strategies for decreasing the problem behavior of children with Autism Spectrum Disorder: a data-based case study. Education and Treatment of Children, 39(1), 64-94.

*Crowell-Davis, S.L., Seibert, L.M., Sung, W.L., Parthasarathy, V., \& Curtis, T.M. (2003). Use of clomipramine, alprazolam, and behavior modification for treatment of storm phobia in dogs. Journal of the American Veterinary Medical Association, 222(6), 744-748.

*Delgado, L.E. \& Lutzker, J.R. (1988). Training Young Parents to Identify and Report Their Children's Illnesses. Journal of Applied Behavior Analysis, 21(3), 311-319.

Diesel, G., Brodbelt, D., \& Pfeiffer, D.U. (2010). Characteristics of relinquished dogs and their owners at 14 rehoming centers in the United Kingdom. Journal of Applied Animal Welfare Science, 13(1), 15-30. DOI: 10.1080/10888700903369255

Diesel, G., Pfeiffer, D.U., \& Brodbelt, D. (2008). Factors affecting the success of rehoming dogs in the UK during 2005. Preventative Veterinary Medicine, 84(3-4), 228-241. DOI: 10.1016/j.prevetmed.2007.12.004

*Dodman, N.H. (2000). Animal behavior case of the month. Journal of the American Veterinary Medical Association, 217(10), 1468-1472. 
*Ducharme, J.M., Popynick, M., \& Steele, S. (1996). Errorless compliance to parental requests .3. Group parent training with parent observational data and long-term follow-up. Behavior Therapy, 27(3), 353-372.

Duffy, D.L., Hsu, Y., \& Serpell, J.A. (2008). Breed differences in canine aggression. Applied Animal Behaviour Science, 114, 441-460. DOI: 10.1016/j.applanim.2008.04.006

*Echterling-Savage, K., DiGennaro-Reed, F.D., Miller, L.K., \& Savage, S. (2014). Effects of caregiver-implemented aggression reduction procedure on problem behavior of dogs. Journal of Applied Animal Welfare Science,18(2), 181-197. DOI: 10.1080/10888705.2014.977383

Edwards, T.L. \& Poling, A. (2011). Animal Research in The Journal of Applied Behavior Analysis. Journal of Applied Behavior Analysis, 44(2), 409-412. DOI: 10.1901/jaba.2011.44-409

Egger, M., Smith, G.D., Schneider, M., \& Minder, C. (1997). Bias in meta-analysis detected by a simple, graphical test. British Medical Journal, 315(7109), 629-634. DOI: 10.1136/bmj.315.7109.629

*Feldman, M.A., Case, L., Garrick, M., MacIntyre-Grande, W., Carnwell, J., \& Sparks, B. (1992). Teaching child-care skills to mothers with developmental disabilities. Journal of Applied Behavior Analysis, 25(1), 205-215.

*Feldman, M.A., Case, L., Rincover, A., Towns, F., \& Betel, J. (1989). Parent Education Project III: increasing affection and responsivity in developmentally handicapped mothers: component analysis, generalization, and effects on child language. Journal of Applied Behavior Analysis, 22(2), 211-222.

*Feldman, M.A., Towns, F., Betel, J., Case, L., Rincover, A., \& Rubino, C.A. (1986). Parent Education Project II: increasing stimulating interactions of developmentally handicapped mothers. Journal of Applied Behavior Analysis, 19(1), 23-37.

*Frank, D. (2005). Animal behavior case of the month. Journal of the American Veterinary Medical Association, 227(6), 890-892.

Fryling, M.J., Wallace, M.D., Yassine, J.N. (2012). Impact of treatment integrity on intervention effectiveness. Journal of Applied Behavior Analysis, 45(2), 449-453. DOI: 10.1901/jaba.2012.45-449

Fukkink, R.G. \& Lont, A. (2007). Does training matter? A meta-analysis and review of caregiver training studies. Early Childhood Research Quarterly, 22(3), 294-311. DOI: https://doi.org/10.1016/j.ecresq.2007.04.005

*Gazzano, A., Mariti, C., Alvares, S., Cozzi, A., Tognetti, R., \& Sighieri, C. (2008). The prevention of undesirable behaviors in dogs: effectiveness of veterinary behaviorists' advice given to puppy owners. Journal of Veterinary Behavior: Clinical Applications and Research, 3(3), 125-133. DOI: 10.1016/j.jveb.2008.04.004 
Germain, S.M., Wilkie, K.D., Milbourne, V.M.K., \& Theule, J. (2018). Animal-assisted psychotherapy and trauma: a meta-analysis. Anthrozoös, 31(2), 141-164. DOI: 10.1080/08927936.2018.1434044

*Giebenhain, J.E. \& O'Dell, S.L. (1984). Evaluation of a parent-training manual for reducing children's fear of the dark. Journal of Applied Behavior Analysis, 17(1), 121-125.

Gravetter, F.J. \& Forzano, L.A.B. (2018). Research Methods for the Behavioral Sciences $\left(6^{\text {th }}\right.$ ed.). Boston, MA, USA: Cengage

Gray, J.M., \& Diller, J.W. (2017). Evaluating the work of applied animal behaviorists as applied behavior analysis. Behavior Analysis: Research and Practice, 17(1), 33-41. DOI: http://dx.doi.org/10.1037/bar0000041

Guyatt, G., Oxman, A.D., Akl, E.A., Kunz, R., Vist, G., Brozek, J., .. Schünemann, H.J. (2011). GRADE guidelines: 1. Introduction - GRADE evidence profiles and summary of findings tables. Journal of Clinical Epidemiology, 64(4), 383-394. DOI:

10.1016/j.jclinepi.2010.04.026

Hare, B., \& Tomasello, M. (2005). Human-like social skills in dogs? Trends in Cognitive Sciences, 9(9), 439-444. DOI: 10.1016/j.tics.2005.07.003

Hart, L. (1995). Dogs as Human Companions: A Review of The Relationship. In J. Serpell (Ed.), The Domestic Dog: Its Evolution, Behavior and Interactions with People (pp. 162178). Cambridge, UK: Cambridge University Press.

*Haydicky, J., Shecter, C., Wiener, J., \& Ducharme, J.M. (2015). Evaluation of MBCT for adolescents with ADHD and their parents: impact on individual and family functioning. Journal of Child and Family Studies, 24(1), 76-94. DOI: 10.1007/s10826-013-9815-1

Hayes, S.C., Zettle, R.D., \& Rosenfarb, I. (1989) Rule-following. In Hayes, S.C. (Ed), RuleGoverned Behavior: Cognition, Contingencies, and Instructional Control (pp. 191-220). New York, NY, USA: Springer Nature Switzerland AG.

Heady, B., \& Grabka, M.M. (2007). Pets and human health in Germany and Australia: national longitudinal results. Social Indicators Research, 80, 297-311. DOI: http://dx.doi.org/10.1007/s11205-005-5072-z

Hedges, L.V., Pustejovsky, J.E., Shadish, W.R. (2012). A standardized mean difference effect size for single case designs. Research Synthesis Methods, 3(3), 224-239. DOI: 10.1002/jrsm.1052

*Heitzman-Powell, L.S., Buzhardt, J., Rusinko, L.C., \& Miller, T.M. (2009). Formative evaluation of an ABA outreach training program for parents of children with Autism in remote areas. Focus on Autism and Other Developmental Disabilities, 30(5), 23-38. DOI: $10.1177 / 1088357613504992$

*Herbert, E.W., Pinkston, E.M., Loeman, H.M., Sajwaj, T.E., Pinkston, S., Cordura, G., \& Jackson, C. (1973). Adverse effects of differential parental attention. Journal of Applied Behavior Analysis, 6(1), 15-30. 
Higgins, J.P., \& Green, S. (2011). Cochrane Handbook for Systematic Reviews of Interventions (Version 5.1.0). Retrieved from http://handbook-5-1.cochrane.org Accessed June $1^{\text {st }}, 2018$

Higgins, J.P., \& Thompson, S.G. (2002). Quantifying heterogeneity in meta-analysis. Statistics in Medicine, 21, 1539-1558. DOI: 10.1002/sim.1186

Horner, R.H., Carr, E.G., Halle, J., McGee, G., Odom, S., \& Wolery, M. (2005). The use of single-subject research to identify evidence-based practice in special education. Exceptional Children, 71(2), 165-179. DOI: 10.1177/001440290507100203

Houpt, K.A., Honig, S.U., \& Reisner, I.R. (1996). Breaking the human-companion animal bond. Journal of the American Veterinary Medical Association, 208(10), 1653-1659.

Howard, V.J., \& DiGennaro-Reed, F.D. (2014). Training shelter volunteers to teach dog compliance. Journal of Applied Behavior Analysis, 47(2), 344-359. DOI: 10.1002/jaba.120

*Hsieh, H.H., Wilder, D.A., \& Abellon, E.O. (1980). The Effects of Training on Caregiver Implementation of Incidental Teaching. Journal of Applied Behavior Analysis, 13(2), 199203.

Hurtado-Parrado, C. \& Lopez-Lopez, W. (2015). Single-case research methods: history and suitability for a psychological science in need of alternatives. Integrative Psychological and Behavioral Science, 49(3), 323-349. DOI: 10.1007/s12124-014-9290-2

*Ilg, J., Jebrane, A., Paquet, A., Rousseau, M., Dutray, B., Wolgensinger, L., \& Clement, C. (2016). Evaluation of a French parent-training program in young children with autism spectrum disorder. Psychologie Francaise, 63(2), 181-199. DOI: 10.1016/j.psfr.2016.12.004

*Jang, J., Tarbox, J., Granpeesheh, D., Kornack, J., de Nocker, Y. \& Dixon, D.R. (2012). Randomized Trial of an eLearning Program for Training Family Members of Children with Autism in the Principles and Procedures of Applied Behavior Analysis. Research in Autism Spectrum Disorders, 6(2), 852-856. DOI: 10.1016/j.rasd.2011.11.004

Johnston, J.M., Pennypacker, H.S. (1993) Within Subject Versus Between Groups Designs: Comparing Experimental Outcomes. In: Johnston, J.M., Pennypacker, H.S. (Eds), Readings for Strategies and Tactics of Behavioral Research. Hillsdale, NJ, USA: Lawrence Erlbaum Associates, Publishers.

*Joyce, S.M. \& Sloane, H.N. (1976). The Generalization Effects of Parent Training Across Stimulus Settings. Journal of Applied Behavior Analysis, 9(3), 355-370.

Keenan, C. (2018). Universal Preschool-and School-Based Education Programmes for Reducing Ethnic Prejudice and Promoting Respect for Diversity among Childeren Aged 311: A Systematic Review and Meta-Analysis (Doctoral dissertation). School of Social Sciences, Education and Social Work, Queen's University Belfast, Belfast, UK.

Kimmel, A.J. (2007) Ethical Issues in Behavioral Research: Basic and Applied Perspectives. Oxford, UK, Blackwell Publishing. 
*Kirkpatrick, R.A. (1972). Learning theory in the treatment of chronic disease. Northwest Medicine, 71(12), 899-902.

*Koegel, R.L., Glahn, T.J., \& Nieminen, G.S. (1978). Generalization of parent-training results. Journal of Applied Behavior Analysis, 11(1), 95-109.

Kratochwill, T.R., Hitchcock, J., Horner, R.H., Levin, J.R., Odom, S.L., Rindskopf, D.M., \& Shadish, W.R. (2010). What Works Clearinghouse: Single-case designs technical documentation. Retrieved from

https://ies.ed.gov/ncee/wwc/Docs/ReferenceResources/wwc scd.pdf Accessed June 20 2018

Kwan, J.Y., \& Bain, M.J. (2013). Owner attachment and problem behaviors related to relinquishment and training techniques of dogs. Journal of Applied Animal Welfare Science, 16(2), 168-183. DOI: 10.1080/10888705.2013.768923

*Lafasakis, M. \& Sturmey, P. (2007). Training parent implementation of Discrete-Trial Teaching: effects on generalization of parent teaching and child correct responding. Journal of Applied Behavior Analysis, 40(4), 685-689. DOI: 10.1901/jaba.2007.685-689

*Laski, K.E., Charlop, M.H., \& Schreibman, L. (1988). Training parents to use the Natural Language Paradigm to increase their Autistic children's speech. Journal of Applied Behavior Analysis, 21(4), 391-400.

*Lem, M. (2002). Behavior modification and pharmacotherapy for separation anxiety in a 2year-old pointer cross. Canadian Veterinary Journal [Revue Veterinaire Canadienne], 43(3), 220-222.

Liberati, A., Altman, D.G., Tetzlaff, J., Mulrow, C., Gotzsche, P.C., Ioannidis, J.P.A., ... Moher, D. (2009). The PRISMA Statement for reporting systematic reviews and metaanalyses of studies that evaluate health care interventions: explanation and elaboration. PLoS Med, 6(7), e1000100. DOI: 10.1371/journal.pmed.1000100

*Lindgren, S., Wacker, D., Suess, A., Schieltz, K., Pelzel, K., Kopelman, T., Lee, J., Romani, P., \& Waldron, D. (2016). Telehealth and Autism: treating challenging behavior at lower cost. Pediatrics, 137(S2), S168-S175. DOI: 10.1542/peds.2015-2851O

Lipsey, M.W., \& Wilson, D.B. (2001). Practical Meta-Analysis. London,UK, Sage Publications.

Littell, J.H., Corcoran, J., Pillai, V. (2008). Systematic reviews and meta-analysis. New York, NY, USA: Oxford University Press

*Lucyshyn, J.M., Fossett, B., Bakeman, R., Cheremshynski, C., Miller, L., Lohrmann, S., Binnendyk, L., Khan, S., Chinn, S., Kwon, S., \& Irvin, L.K. (2015). Transforming parentchild interaction in family routines: longitudinal analysis with families of children with developmental disabilities. Journal of Child and Family Studies, 24(12), 3526-3541. DOI: $10.1007 / \mathrm{s} 10826-015-0154-2$ 
Maharaj, N., Haney, C.J. (2015). A qualitative investigation of the significance of companion dogs. Western Journal of Nursing Research, 37(9), 1175-1193. DOI:

$0.1177 / 0193945914545176$

*Miles, N.I. \& Wilder, D.A. (2009). The effects of Behavioral Skills Training on caregiver implementation of guided compliance. Journal of Applied Behavior Analysis, 42(2), 405410. DOI: $10.1901 /$ jaba.2009.42-405

*Miltenberger, R.G., Fogel, V.A., Beck, K.V., Koehler, S., Shayne, R., Noah, J., McFee, K., Perdomo, Andrea, Chan, P., Simmons, D., \& Godish, D. (2013). Efficacy of the Stranger Safety Abduction-Prevention Program and parent-conducted in situ training. Journal of Applied Behavior Analysis, 46(4), 817-820. DOI: 10.1002/jaba.80

*Minjarez-Boettcher, M., Williams, S.E., Mercier, E.M., \& Hardan, A.Y. (2011). Pivotal response group treatment program for parents of children with Autism. Journal of Autism and Developmental Disorders, 41, 92-101. DOI: 10.1007/s10803-010-1027-6

Moher, D., Liberati, A., Tetzlaff, J., Altman, D.G., The PRISMA Group (2009). Preferred Reporting Items for Systematic Reviews and Meta-Analyses: The PRISMA Statement. PLoS Med, 6(7), e1000097. DOI: 10.1371/journal.pmed.1000097

*Mulford, L.A. (2010). Parents' Ability to Identify Social-Communication Behavior in Children with Autism Spectrum Disorders: The Use and Acceptance of Descriptive Assessment Procedures (Doctoral dissertation). Graduate School, University of WisconsinMadison, USA.

*Najdowski, A.C., Wallace, M.D., Reagon, K., Penrod, B., Higbee, T.S., \& Tarbox, J. (2010). Utilizing a home-based parent training approach in the treatment of food selectivity. Behavioral Interventions, 25(2), 89-107. DOI: 10.1002/bin.298

Nederhof, A.J. (1985). Methods of coping with social desirability bias: a review. European Journal of Social Psychology, 15, 263-280. DOI: 10.1002/ejsp.2420150303

*Neef, N.A. (1995). Pyramidal parent training by peers. Journal of Applied Behavior Analysis, 28(3), 333-337.

Nelson, M.S., Wooditch, A., \& Dario, L.M. (2014). Sample size, effect size, and statistical power: a replication study of Weisburd's paradox. Journal of Experimental Criminology. DOI: $10.1007 / \mathrm{s} 11292-014-9212-9$

Neyeloff, J.L., Fuchs, S.C., \& Moreira, L.B. (2012). Meta-analyses and forest plots using a Microsoft excel spreadsheet: step-by-step guide focusing on descriptive data analysis. BMC Research Notes, 5(52). DOI: 10.1186/1756-0500-5-52

*Overall, K.L. (1998). Animal behavior case of the month. Journal of the American Veterinary Medical Association, 213(1), 34-36.

*Pangborn, M.M., Borrero, C.S.W., \& Borrero, J.C. (2013). Sequential application of caregiver training to implement pediatric feeding protocols. Behavioral Interventions, 28(2), 107-130. DOI: 10.1002/bin.1356 
Petticrew, M., \& Roberts, H. (2006). Systematic Reviews in the Social Sciences: A Practical Guide. Malden, MA, USA, Blackwell Publishing.

*Pelham, W.E., Schnedler, R.W., Bologna, N.C., \& Contreras, J.A. (1980). Behavioral and stimulant treatment of hyperactive children: a therapy study with methylphenidate probes in a within-subject design. Journal of Applied Behavior Analysis, 13(2), 221-236.

Pierce, W.D., \& Cheney, C.D. (2013). Behavior Analysis and Learning (5 ${ }^{\text {th }}$ ed.). New York and London, Psychology Press.

Pierce, W.D., \& Cheney, C.D. (2017). Behavior Analysis and Learning: A Biobehavioral Approach (6 ${ }^{\text {th }}$ ed.). New York, NY, USA: Routledge.

* Pike, A.L. (2016). Animal behavior case of the month. Journal of the American Veterinary Medical Association, 249(12), 1367-1370.

*Podberscek, A.L., Hsu, Y., \& Serpell, J. A. (1999). Evaluation of clomipramine as an adjunct to behavioural therapy in the treatment of separation-related problems in dogs. Veterinary Record, 145(13), 365-369.

Prato-Previde, E., Custance, D.M., Spiezio, C., \& Sabatini, F. (2003). Is the dog-human relationship an attachment bond? An observational study using Ainsworth's Strange Situation. Behavior, 140, 225-254. DOI: http://www.jstor.org/stable/4536022

Prato-Previde, E., \& Valsecchi, P. (2014). The Immaterial Cord: The Dog-Human Attachment Bond. In J. Kaminski, \& S. Marshall-Pescini (Eds.), The Social Dog: Behavior and Cognition (pp. 165-189). London, UK: Elsevier Inc. DOI: 10.1016/B978-0-12-4078185.00006-1

* Pryor, P. (2003). Animal behavior case of the month. Journal of the American Veterinary Medical Association, 223(6), 790-792.

*Reich, M.R. (1999). Animal behavior case of the month. Journal of the American Veterinary Medical Association, 215(12), 1780-1782.

Reichow, B. (2012). Overview of meta-analyses on Early Intensive Behavioral Intervention for Young Children with Autism Spectrum Disorders. Journal of Autism Developmental Disorders, 42, 512-520. DOI: 10.1007/s10803-011-1218-9

*Reitzel, J., Summers, J., Lorv, B., Szatmari, P., Zwaigenbaum, L., Georgiades, S., \& Duku, E. (2013). Pilot randomized controlled trial of a Functional Behavior Skills Training program for young children with Autism Spectrum Disorder who have significant early learning skill impairments and their families. Research in Autism Spectrum Disorders, 7(11), 1418-1432. DOI: 10.1016/j.rasd.2013.07.025

*Rivard, M., Morin, M., Mercier, C., Terroux, A., Mello, C., \& Lepine, A. (2017). Social validity of a training and coaching program for parents of children with autism spectrum disorder on a waiting list for Early Behavioral Intervention. Journal of Child and Family Studies, 26(3), 877-887. DOI: 10.1007/s10826-016-0604-5 
*Rostad, W.L., McFry, E.A., Self-Brown, S., Damashek, A., \& Whitaker, D.J. (2017). Reducing safety hazards in the home through the use of an evidence-based parenting program. Journal of Child and Family Studies, 26(9), 2602-2609. DOI: 10.1007/s10826017-0756-y

*Rudy, B.M., Zavrou, S., Johnco, C., Storch, E.A., \& Lewin, A.B. (2017). Parent-led exposure therapy: a pilot study of a brief behavioral treatment for anxiety in young children. Journal of Child and Family Studies, 26(9), 2475-2484. DOI: 10.1007/s10826017-0772-y

*Saunders, R., McFarland-Piazza, L., Jacobvitz, D., Hazen-Swann, N., \& Burton, R. (2013). Maternal knowledge and behaviors regarding discipline: the effectiveness of a hands-on education program in positive guidance. Journal of Child and Family Studies, 22, 322-334. DOI: $10.1007 / \mathrm{s} 10826-012-9581-5$

Schoeberl, I., Wedl, M., Bauer, B., Day, J., Möstl, E., \& Kotrschal, K. (2012). Effects of owner-dog relationship and owner personality on cortisol modulation in human-dog dyads. Anthrozoös, 25(2), 122-214. DOI: 10.2752/175303712X13316289505422

*Schoenfelder, E.N., Sandler, I.N., Millsap, R.E., Wolchik, S.A., Berkel, C., \& Ayers, T.S. (2013). Caregiver responsiveness to the family bereavement program: what predicts responsiveness? What does responsiveness predict? Prevention Science, 14(6), 545-556. DOI: $10.1007 / \mathrm{s} 11121-012-0337-7$

*Seiverling, L., Williams, K., Sturmey, P., \& Hart, S. (2012). Effects of Behavioral Skills Training on parental treatment of children's food selectivity. Journal of Applied Behavior Analysis, 45(1), 197-203. DOI: 10.1901/jaba.2012.45-197

*Seksel, K. \& Lindeman, M.J. (2001). Use of clomipramine in treatment of obsessivecompulsive disorder, separation anxiety and noise phobia in dogs: a preliminary, clinical study. Australian Veterinary Journal, 79(4), 252-256.

Skinner, B.F. (1984). An operant analysis of problem solving. The Behavioral and Brain Sciences, 7(4), 583-613. DOI: 10.1017/S0140525X00027412

Stangroom, J. (2018). Social Science Statistics. Retrieved from http://www.socscistatistics.com/Default.aspx Accessed February 28 ${ }^{\text {th }}, 2018$.

*Stelow, L. (2016). Animal Behavior Case of the Month. Journal of the American Veterinary Medical Association, 248(11), 1248-1251.

Sterne, J.A., Gavaghan, D., \& Egger, M. (2000). Publication and related bias in metaanalysis: power of statistical tests and prevalence in the literature. Journal of Clinical Epidemiology, 53(11), 1119-1129. DOI: 10.1016/S0895-4356(00)00242-0

*Stewart, K.K., Carr, J.E., \& LeBlanc, L.A. (2007). Evaluation of family-implemented behavioral skills training for teaching social skills to a child with Asperger's Disorder. Clinical Case Studies, 6(3), 252-262. DOI: 10.1177/1534650106286940 
Sturmey, P. (2009) Case Formulation: A Review and Overview of This Volume. In: Sturmey, P. (Ed) Clinical Case Formulation: Varieties of Approaches. Chichester, West Sussex, UK: John Wiley \& Sons, Ltd.

*Suess, A.N., Wacker, D.P., Schwartz, J.E., Lustig, N., \& Detrick, J. (2016). Preliminary evidence on the use of telehealth in an outpatient behavior clinic. Journal of Applied Behavior Analysis, 49(3), 1-7. DOI: 10.1002/jaba.305

Thalmann, O., Shapiro, B., Cui, P., Schuenemann, V.J., Sawyer, S.K., Greenfield, D.L., ... Wayne, R.K. (2013). Complete mitochondrial genomes of ancient canids suggest a European origin of domestic dogs. Science, 342(6160), 871-874. DOI: 10.1126/science. 1243650

Taylor, P. (2006). Gauging family intimacy: pew research centers social demographic trends project RSS. Pew Research Center. Retrieved from: http://www.pewsocialtrends.org/2006/03/07/gauging-family-intimacy/ Accessed August $28^{\text {th }} 2017$.

Tomasello, M., \& Kaminski, J. (2009). Like infant, like dog. Science, 325(5945), 1213-1214. DOI: $10.1126 /$ science. 1179670

Topal, J., Miklósi, Á., Csányi, V. \& Dóka, A. (1998). Attachment behavior in dogs (Canis familiaris): a new application of Ainsworth's (1969) Strange Situation Test. Journal of Comparative Psychology, 112(3), 219-229. DOI: 10.1037/0735-7036.112.3.219.

Udell, M.A.R. \& Wynne, C.D.L. (2008). A review of domestic dogs' (Canis familiaris) human-like behaviors: or why behavior analysts should stop worrying and love their dogs. Journal of the Experimental Analysis of Behavior, 89(2), 247-261. DOI: $10.1901 /$ jeab.2008.89-247

Van Camp, C.M. (2018). Behavior Analysis in Child Welfare: A Preliminary Program Evaluation (Doctoral dissertation). Department of Psychology, Graduate Faculty of the Louisiana State University and Agricultural and Mechanical College, USA.

Van Herwijnen, I.R., van der Borg, J.A.M., Naguib, M., \& Beerda, B. (2018). The existence of parenting styles in the owner-dog relationship. PLOS ONE, 13(2), e0193471. Retrieved from https://doi.org/10.1371/journal.pone.0193471 Accessed June 20 2018

Virues-Ortega, J. \& Moreno-Rodriguez, R. (2008). Guidelines for clinical case reports in behavioral clinical psychology. International Journal of Clinical and Health Psychology, 8(3), 765-777. Retrieved from http://www.aepc.es/ijchp/virues-en.pdf Accessed June $10^{\text {th }}$ 2017

*Voith, V.L. (1980). Play behavior interpreted as aggression or hyperactivity: case histories. Modern Veterinary Practice, 707-709.

*Wahler, R.G., Vigilante, A.V., \& Strand, P.S. (2004). Generalization in a child's oppositional behavior across home and school settings. Journal of Applied Behavior Analysis, 37(1), 43-51. 
Wells, D.L., \& Hepper, P.G. (2000). Prevalence of behavior problems reported by owners of dogs purchased from an animal rescue shelter. Applied Animal Behavior Science, 69(1), 55-65. DOI: 10.1016/S0168-1591(00)00118-0

Weng, H.Y., Kass, P.H., Hart, L.A., \& Chomel, B.B. (2006). Risk factors for unsuccessful dog ownership: an epidemiologic study in Taiwan. Preventative Veterinary Medicine, 77, 82-95. DOI: 10.1016/j.prevetmed.2006.06.004

Westgarth, C., Christian, H.E. \& Christley, R.M. (2015). Factors associated with daily walking of dogs. BMC Veterinary Research, 11(1), 116-128. DOI: 10.1186/s12917-0150434-5.

Westgarth, C., Christley, R.M., \& Christian, H.E. (2014). How might we increase physical activity through dog walking? A comprehensive review of dog walking correlates. International Journal of Behavioral Nutrition and Physical Activity, 11, 83-97. Retrieved from http://www.ijbnpa.org/content/11/1/83 Accessed March 172017

*Young, K.L., Boris, A.L., Thomson, K.M., Martin, G.L., \& Yu, C.T. (2012). Evaluation of a self-instructional package on discrete-trials teaching to parents of children with autism. Research in Autism Spectrum Disorders, 6(4), 1321-1330. DOI:

10.1016/j.rasd.2012.05.001 


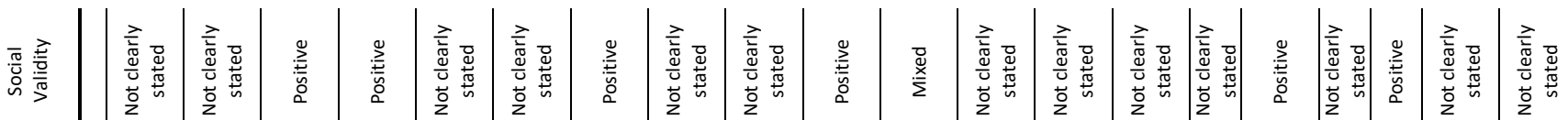

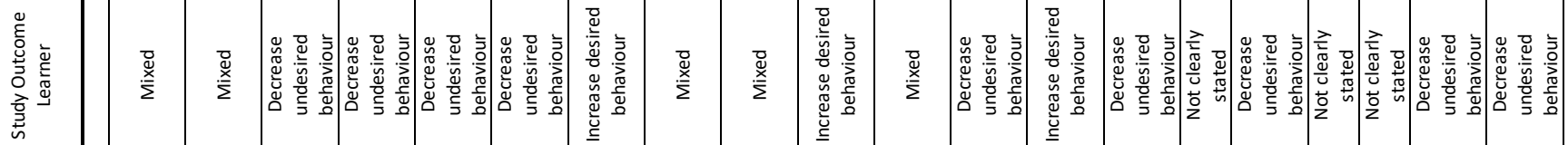

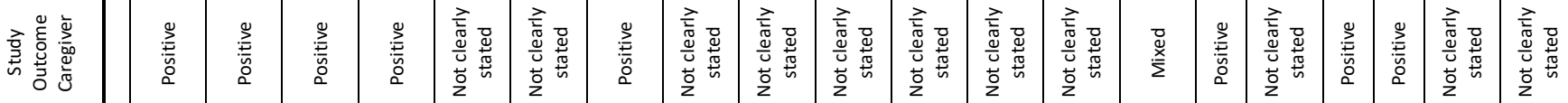

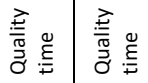

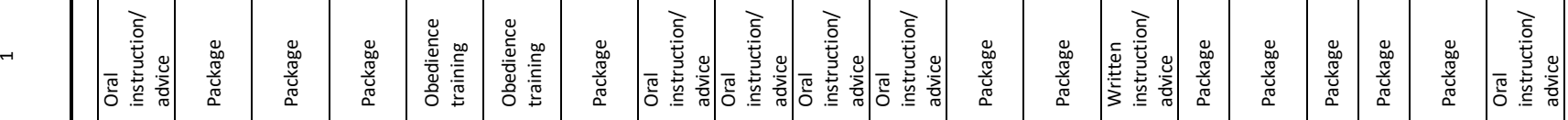

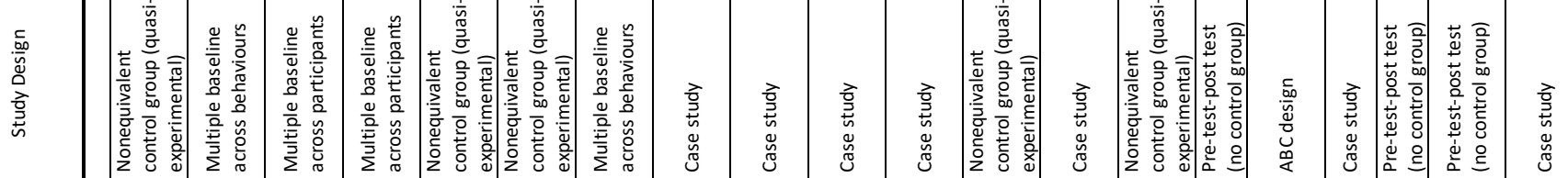

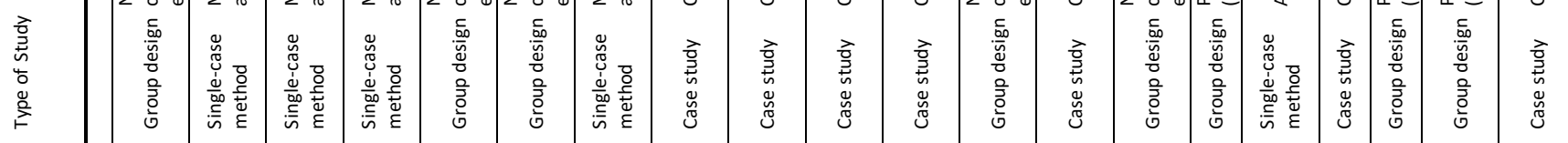

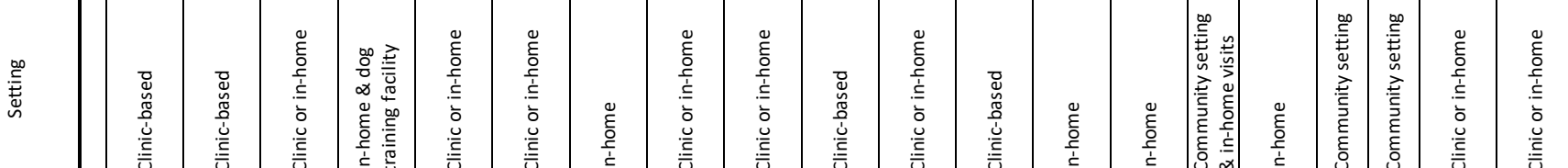

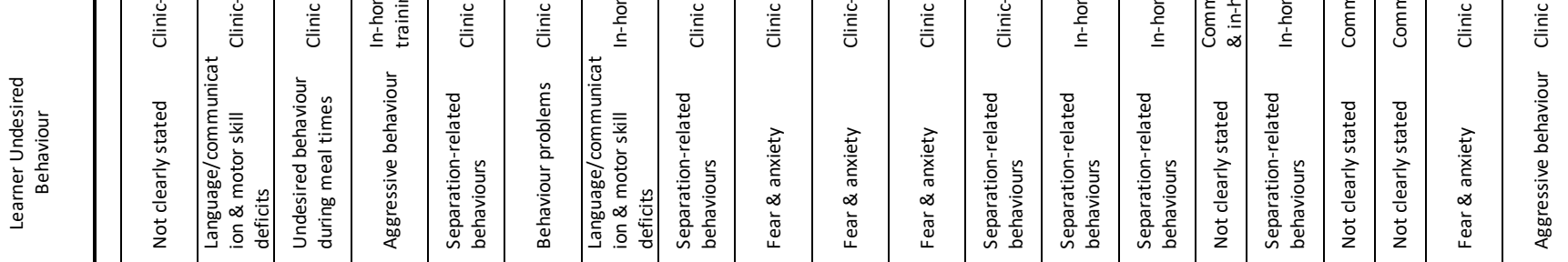

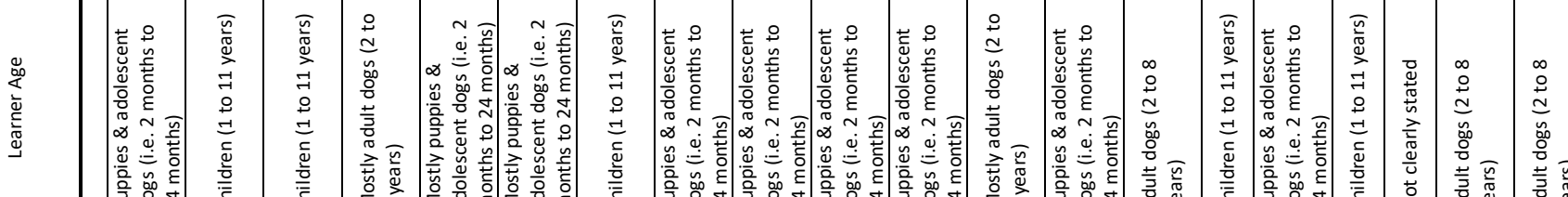

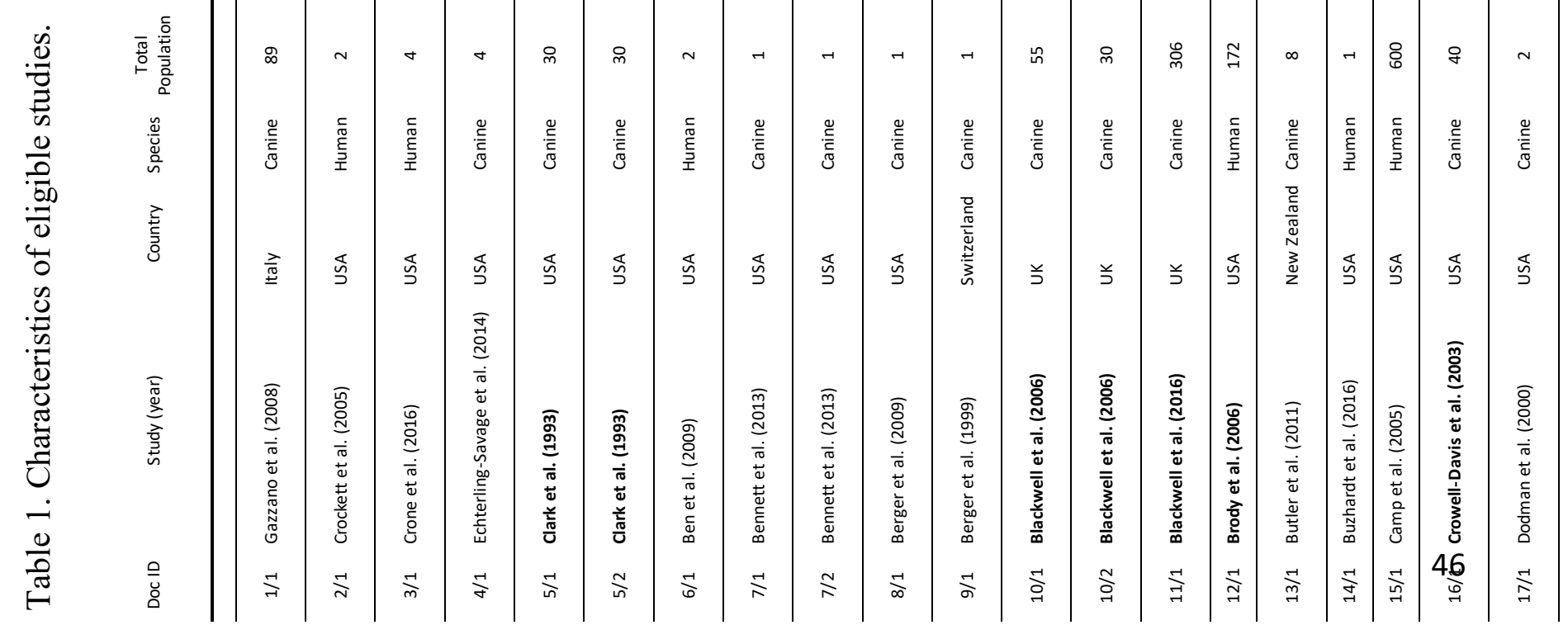




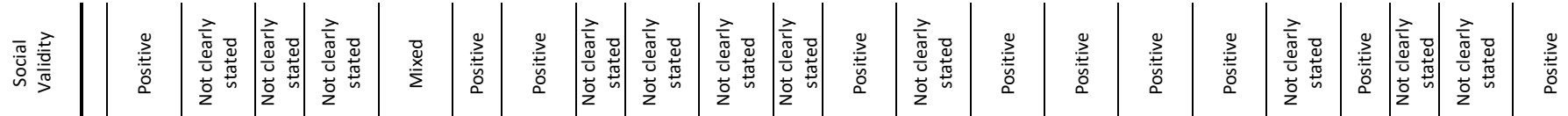

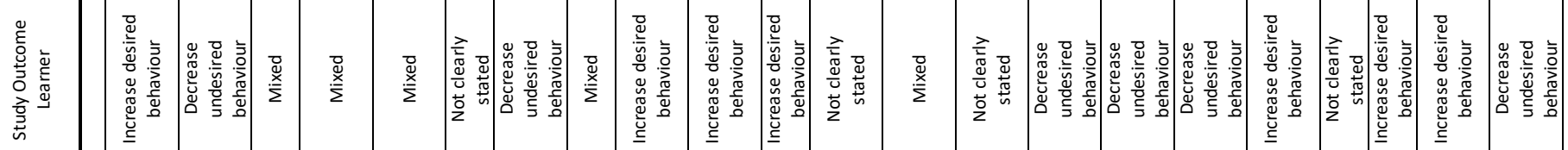

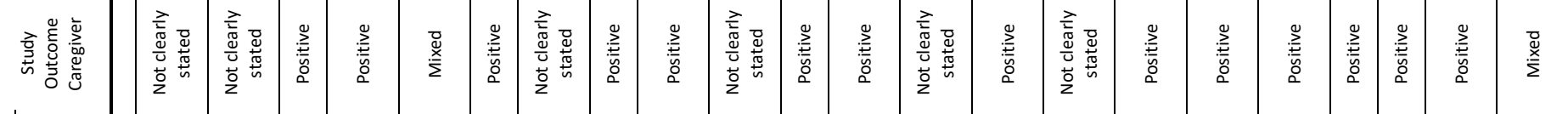

童

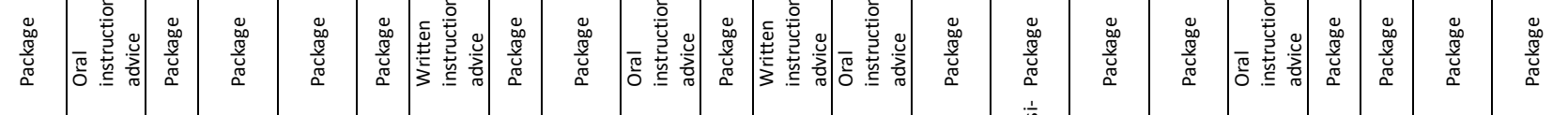

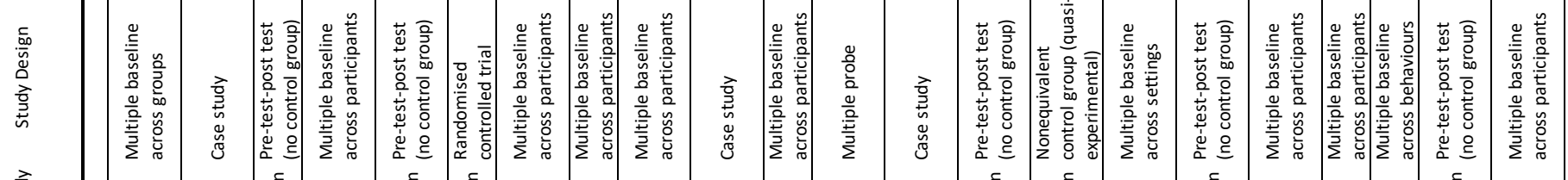

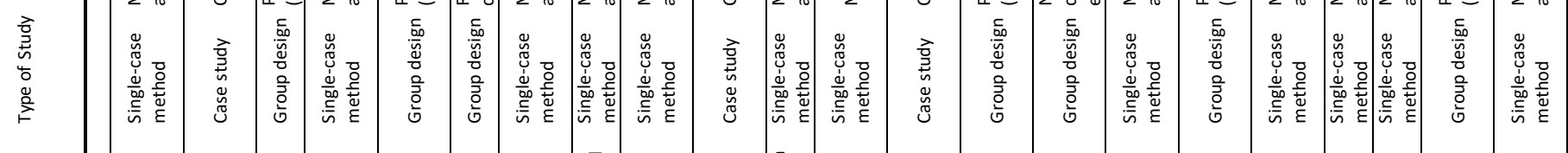

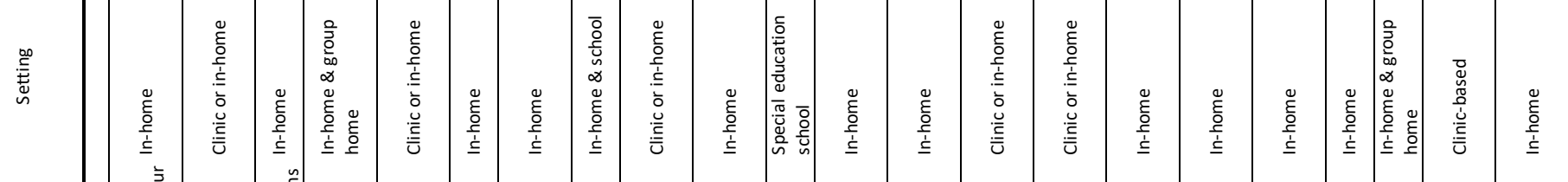

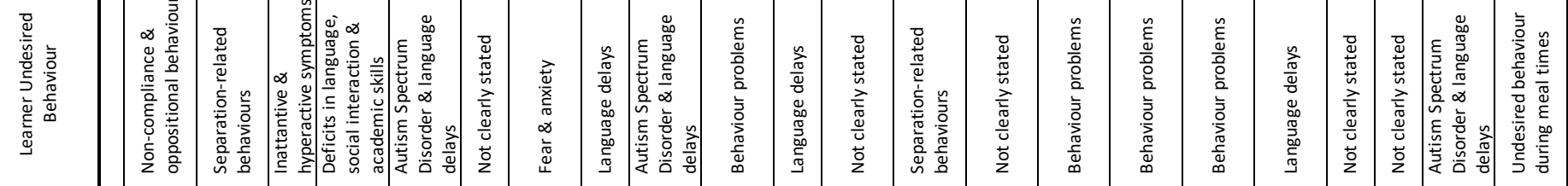

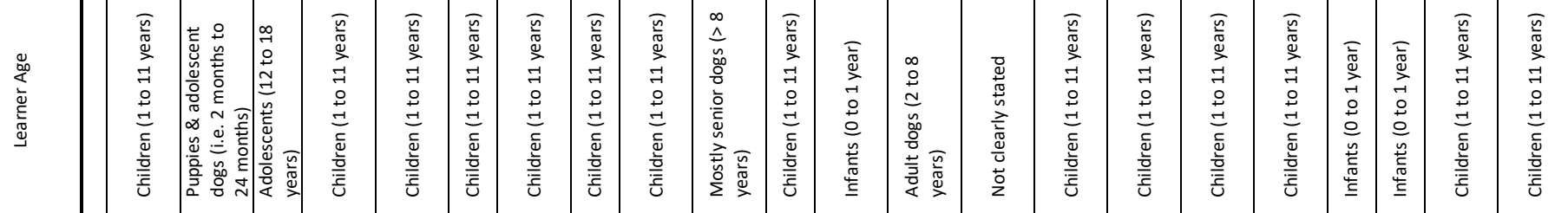

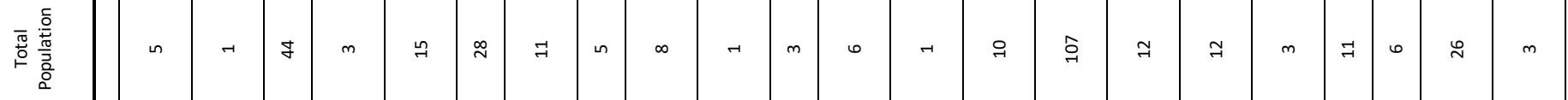
䆓

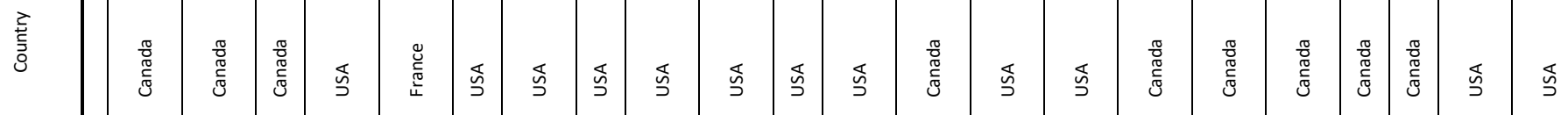

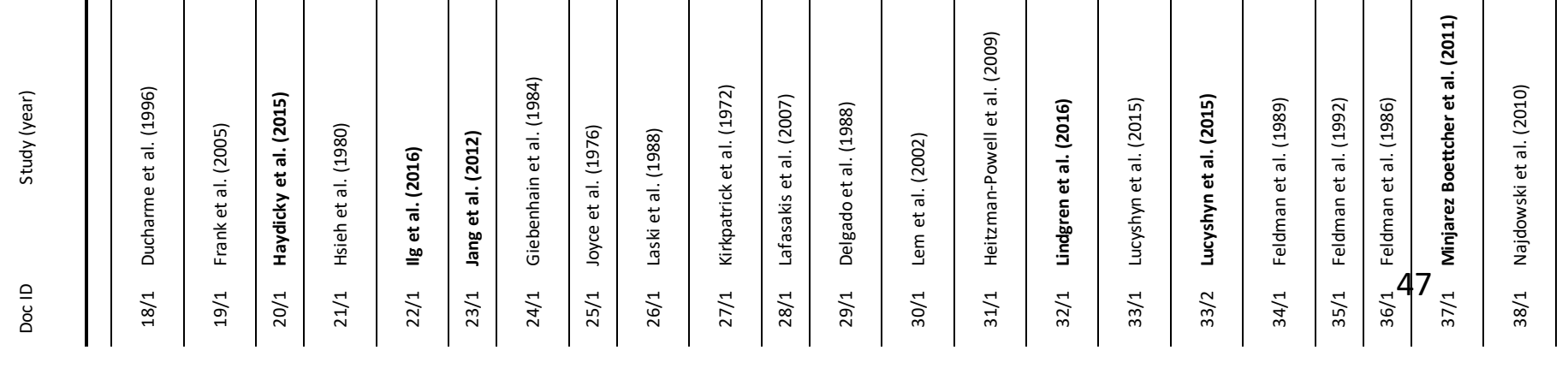




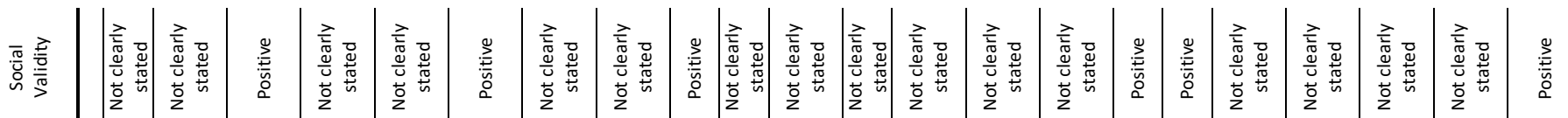

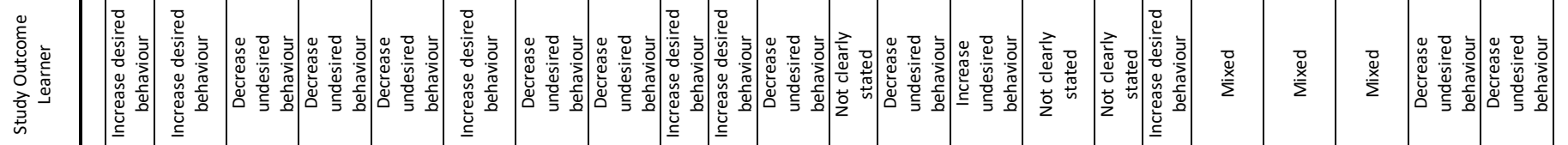

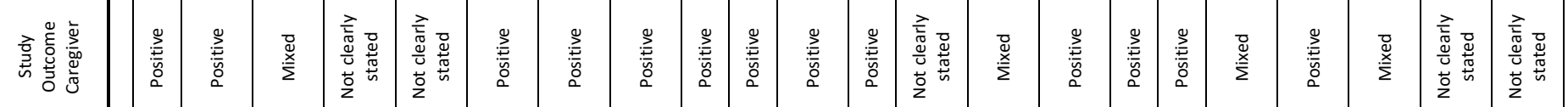

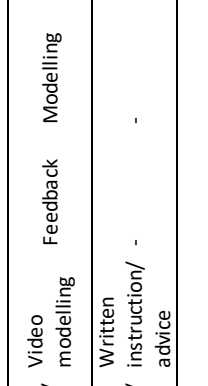

\section{产}

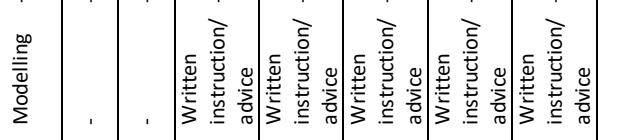

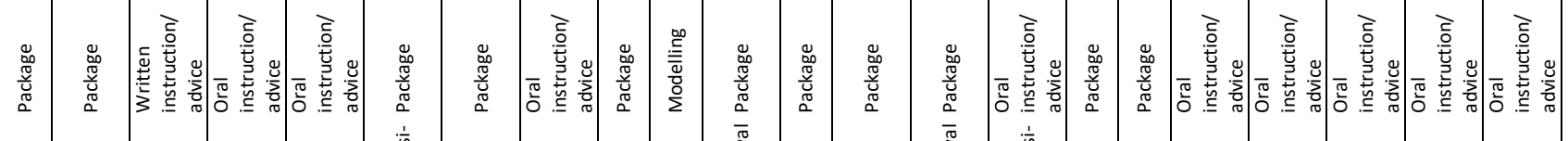

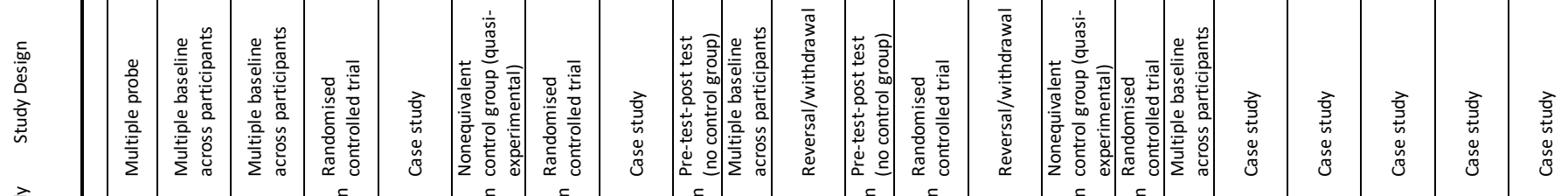

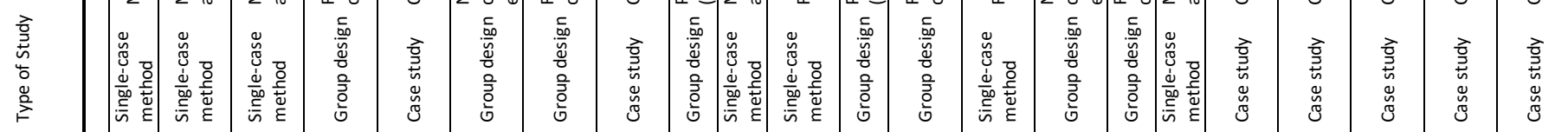

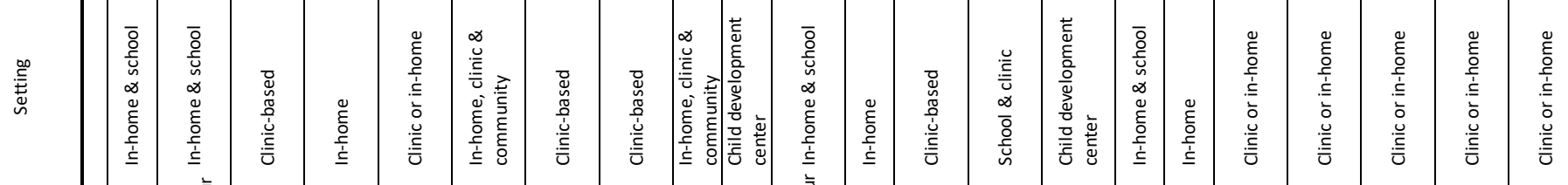

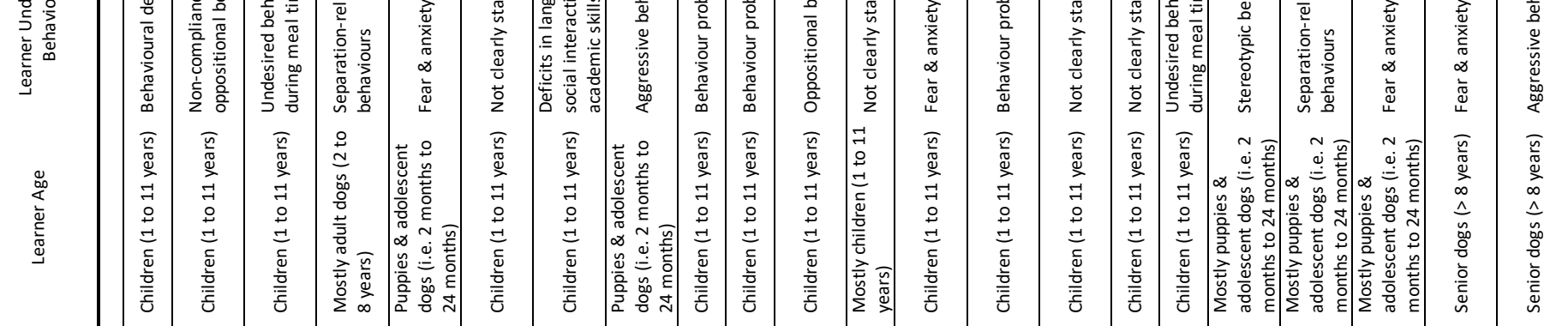

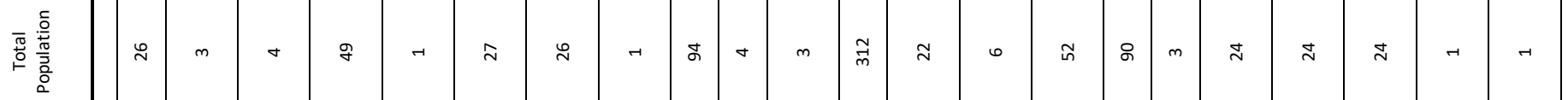

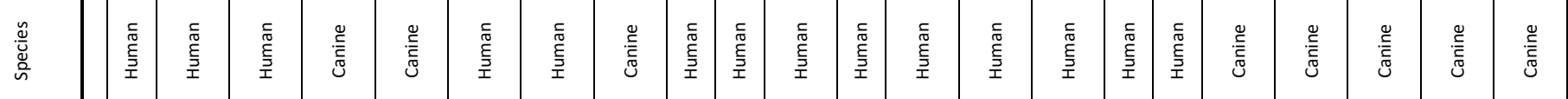

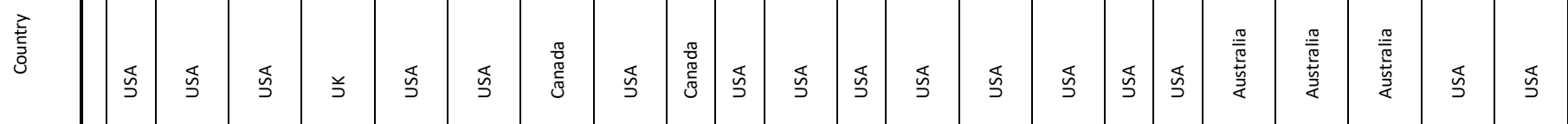

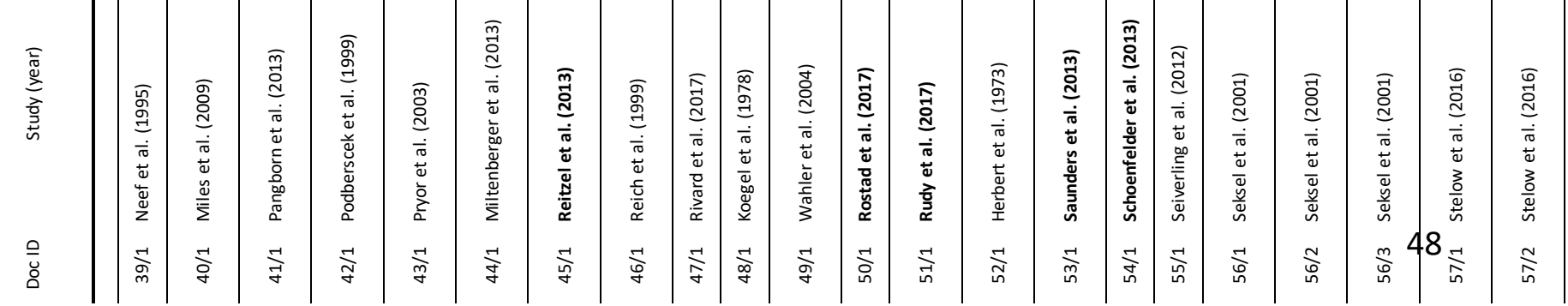




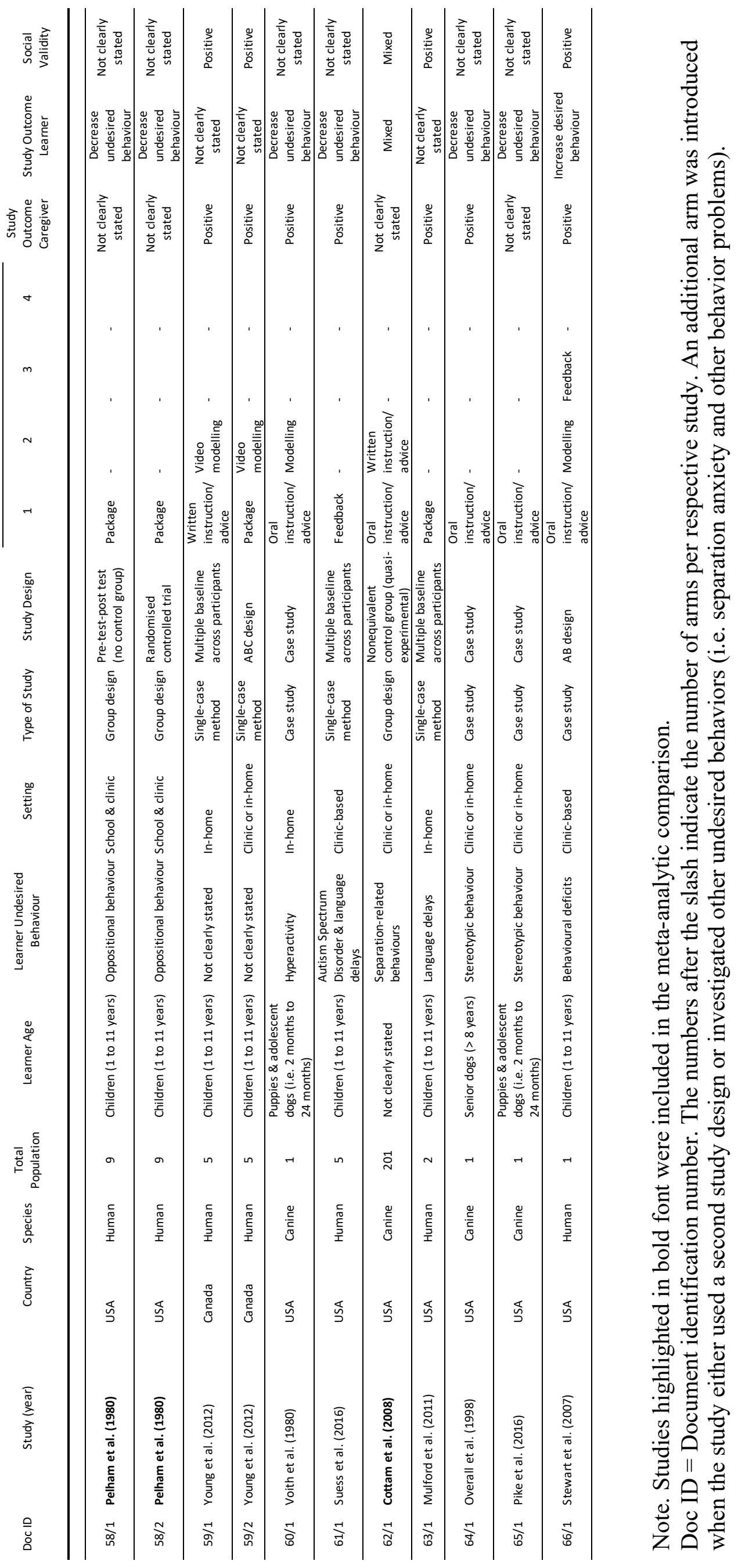


Table 2. Participant characteristics of included studies displayed by canine- and humanrelated studies across all designs.

\begin{tabular}{|c|c|c|c|c|c|c|c|}
\hline \multicolumn{2}{|c|}{ Participant characteristic of included studies } & & & & & & \\
\hline Characteristic & Type & Human & Canine & Human & Canine & Count & Percent \\
\hline Single-case designs & & & & & & & \\
\hline Caregiver Population & Mothers & 16 & 0 & $57 \%$ & $0 \%$ & 16 & $57 \%$ \\
\hline & Universal (both female and male participants) & 7 & 0 & $25 \%$ & $0 \%$ & 7 & $25 \%$ \\
\hline & Not clearly stated & 0 & 2 & $0 \%$ & $7 \%$ & 2 & $7 \%$ \\
\hline & Parents \& other caregivers & 2 & 0 & $7 \%$ & $0 \%$ & 2 & $7 \%$ \\
\hline & Both parents & 1 & 0 & $4 \%$ & $0 \%$ & 1 & $4 \%$ \\
\hline & TOTAL & 26 & 2 & $93 \%$ & $7 \%$ & 28 & $100 \%$ \\
\hline Caregiver Education & Not clearly stated & 15 & 2 & $54 \%$ & $7 \%$ & 17 & $61 \%$ \\
\hline & Low (secondary school) & 6 & 0 & $21 \%$ & $0 \%$ & 6 & $21 \%$ \\
\hline & Medium (under graduate) & 5 & 0 & $18 \%$ & $0 \%$ & 5 & $18 \%$ \\
\hline & TOTAL & 26 & 2 & $93 \%$ & $7 \%$ & 28 & $100 \%$ \\
\hline Caregiver Gender & All female & 17 & 0 & $61 \%$ & $0 \%$ & 17 & $61 \%$ \\
\hline & Mostly female & 5 & 0 & $18 \%$ & $0 \%$ & 5 & $18 \%$ \\
\hline & Not clearly stated & 1 & 2 & $4 \%$ & $7 \%$ & 3 & $11 \%$ \\
\hline & Both & 3 & 0 & $11 \%$ & $0 \%$ & 3 & $11 \%$ \\
\hline & TOTAL & 26 & 2 & $93 \%$ & $7 \%$ & 28 & $100 \%$ \\
\hline Learner Gender/Sex & All male & 9 & 0 & $32 \%$ & $0 \%$ & 9 & $32 \%$ \\
\hline & Mostly male & 8 & 0 & $29 \%$ & $0 \%$ & 8 & $29 \%$ \\
\hline & Mostly female & 5 & 1 & $18 \%$ & $4 \%$ & 6 & $21 \%$ \\
\hline & Both & 2 & 1 & $7 \%$ & $4 \%$ & 3 & $11 \%$ \\
\hline & Not clearly stated & 2 & 0 & $7 \%$ & $0 \%$ & 2 & $7 \%$ \\
\hline & TOTAL & 26 & 2 & $93 \%$ & $7 \%$ & 28 & $100 \%$ \\
\hline Learner Age & Children (1 to 11 years) & 23 & 0 & $82 \%$ & $0 \%$ & 23 & $82 \%$ \\
\hline & Infants ( 0 to 1 year) & 3 & 0 & $11 \%$ & $0 \%$ & 3 & $11 \%$ \\
\hline & Mostly adult dogs (2 to 8 years) & 0 & 1 & $0 \%$ & $4 \%$ & 1 & $4 \%$ \\
\hline & Puppies $\&$ adolescent dogs (i.e. 2 months to 24 months) & 0 & 1 & $0 \%$ & $4 \%$ & 1 & $4 \%$ \\
\hline & TOTAL & 26 & 2 & $93 \%$ & $7 \%$ & 28 & $100 \%$ \\
\hline Group designs & 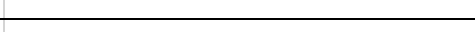 & & & 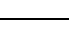 & & & \\
\hline $\begin{array}{l}\text { Group designs } \\
\text { Caregiver Population }\end{array}$ & Universal (both female and male participants) & 12 & 3 & $48 \%$ & $12 \%$ & 15 & $60 \%$ \\
\hline & Not clearly stated & 0 & 4 & $0 \%$ & $16 \%$ & 4 & $16 \%$ \\
\hline & Mothers & 4 & 0 & $16 \%$ & $0 \%$ & 4 & $16 \%$ \\
\hline & Both parents & 1 & 0 & $4 \%$ & $0 \%$ & 1 & $4 \%$ \\
\hline & Parents \& other caregivers & 1 & 0 & $4 \%$ & $0 \%$ & 1 & $4 \%$ \\
\hline & TOTAL & 18 & 7 & $72 \%$ & $28 \%$ & 25 & $100 \%$ \\
\hline Caregiver Education & Not clearly stated & 10 & 6 & $40 \%$ & $24 \%$ & 16 & $64 \%$ \\
\hline & Medium (under graduate) & 6 & 0 & $24 \%$ & $0 \%$ & 6 & $24 \%$ \\
\hline & Low (secondary school) & 2 & 1 & $8 \%$ & $4 \%$ & 3 & $12 \%$ \\
\hline & TOTAL & 18 & 7 & $72 \%$ & $28 \%$ & 25 & $100 \%$ \\
\hline Caregiver Gender & Not clearly stated & 6 & 5 & $24 \%$ & $20 \%$ & 11 & $44 \%$ \\
\hline & Mostly female & 4 & 2 & $16 \%$ & $8 \%$ & 6 & $24 \%$ \\
\hline & All female & 4 & 0 & $16 \%$ & $0 \%$ & 4 & $16 \%$ \\
\hline & Both & 4 & 0 & $16 \%$ & $0 \%$ & 4 & $16 \%$ \\
\hline & TOTAL & 18 & 7 & $72 \%$ & $28 \%$ & 25 & $100 \%$ \\
\hline Learner Gender/Sex & Mostly male & 8 & 3 & $33 \%$ & $12 \%$ & 11 & $44 \%$ \\
\hline & Not clearly stated & 3 & 2 & $12 \%$ & $8 \%$ & 5 & $20 \%$ \\
\hline & Both & 5 & 0 & $20 \%$ & $0 \%$ & 5 & $20 \%$ \\
\hline & Mostly female & 1 & 2 & $4 \%$ & $8 \%$ & 3 & $12 \%$ \\
\hline & All male & 1 & 0 & $4 \%$ & $0 \%$ & 1 & $4 \%$ \\
\hline & TOTAL & 18 & 7 & $72 \%$ & $28 \%$ & 25 & $100 \%$ \\
\hline & & & & & & & \\
\hline Learner Age & $\begin{array}{l}\text { Children (1 to } 11 \text { years) } \\
\text { Not clearly stated }\end{array}$ & $\frac{14}{2}$ & 0 & $\begin{array}{c}56 \% \\
8 \%\end{array}$ & $\begin{array}{l}0 \% \\
4 \%\end{array}$ & $\begin{array}{c}14 \\
3\end{array}$ & $\begin{array}{l}56 \% \\
12 \%\end{array}$ \\
\hline & Adult dogs (2 to 8 years) & 0 & 2 & $0 \%$ & $8 \%$ & 2 & $8 \%$ \\
\hline & Mostly adult dogs ( 2 to 8 years) & 0 & 2 & $0 \%$ & $8 \%$ & 2 & $8 \%$ \\
\hline & Adolescents (12 to 18 years) & 1 & 0 & $4 \%$ & $0 \%$ & 1 & $4 \%$ \\
\hline & Puppies $\&$ adolescent dogs (i.e. 2 months to 24 months) & 0 & 1 & $0 \%$ & $4 \%$ & 1 & $4 \%$ \\
\hline & Mostly children (1 to 11 years) & 1 & 0 & $4 \%$ & $0 \%$ & 1 & $4 \%$ \\
\hline & Mostly puppies \& adolescent dogs (i.e. 2 months to 24 months) & 0 & 1 & $0 \%$ & $4 \%$ & 1 & $4 \%$ \\
\hline & TOTAL & 18 & 7 & $72 \%$ & $28 \%$ & 25 & $100 \%$ \\
\hline Case studies & & & & & & & \\
\hline Caregiver Population & Universal (both female and male participants) & 0 & 7 & $0 \%$ & $41 \%$ & 7 & $41 \%$ \\
\hline & Not clearly stated & 0 & 6 & $0 \%$ & $35 \%$ & 6 & $35 \%$ \\
\hline & Female dog owners & 0 & 2 & $0 \%$ & $12 \%$ & 2 & $12 \%$ \\
\hline & Mothers & 1 & 0 & $6 \%$ & $0 \%$ & 1 & $6 \%$ \\
\hline & Parents \& other caregivers & 1 & 0 & $6 \%$ & $0 \%$ & 1 & $6 \%$ \\
\hline & TOTAL & 2 & 15 & $12 \%$ & $88 \%$ & 17 & $100 \%$ \\
\hline Caregiver Education & Not clearly stated & 1 & 14 & $6 \%$ & $82 \%$ & 15 & $88 \%$ \\
\hline & Low (secondary school) & 1 & 0 & $6 \%$ & $0 \%$ & 1 & $6 \%$ \\
\hline & Medium (under graduate) & 0 & 1 & $0 \%$ & $6 \%$ & 1 & $6 \%$ \\
\hline & TOTAL & 2 & 15 & $12 \%$ & $88 \%$ & 17 & $100 \%$ \\
\hline Caregiver Gender & Both & 0 & 7 & $0 \%$ & $41 \%$ & 7 & $41 \%$ \\
\hline & Not clearly stated & 0 & 6 & $0 \%$ & $35 \%$ & 6 & $35 \%$ \\
\hline & All female & 2 & 2 & $12 \%$ & $12 \%$ & 4 & $24 \%$ \\
\hline & TOTAL & 2 & 15 & $12 \%$ & $88 \%$ & 17 & $100 \%$ \\
\hline Learner Gender/Sex & Male/neutered & 0 & 6 & $0 \%$ & $35 \%$ & 6 & $35 \%$ \\
\hline & Female/neutered & 0 & 3 & $0 \%$ & $18 \%$ & 3 & $18 \%$ \\
\hline & Female/intact & 0 & 3 & $0 \%$ & $18 \%$ & 3 & $18 \%$ \\
\hline & Not clearly stated & 0 & 2 & $0 \%$ & $12 \%$ & 2 & $12 \%$ \\
\hline & All male & 2 & 0 & $12 \%$ & $0 \%$ & 2 & $12 \%$ \\
\hline & Both & 0 & 1 & $0 \%$ & $6 \%$ & 1 & $6 \%$ \\
\hline & TOTAL & 2 & 15 & $12 \%$ & $88 \%$ & 17 & $100 \%$ \\
\hline Learner Age & Puppies \& adolescent dogs (i.e. 2 months to 24 months) & 0 & 9 & $0 \%$ & $53 \%$ & 9 & $53 \%$ \\
\hline & Senior dogs (> 8 years) & 0 & 2 & $0 \%$ & $12 \%$ & 2 & $12 \%$ \\
\hline & Children (1 to 11 years) & 2 & 0 & $12 \%$ & $0 \%$ & 2 & $12 \%$ \\
\hline & Adult dogs ( 2 to 8 years) & 0 & 2 & $0 \%$ & $12 \%$ & 2 & $12 \%$ \\
\hline & Mostly senior dogs ( $>8$ years) & 0 & 1 & $0 \%$ & $6 \%$ & 1 & $6 \%$ \\
\hline & Mostly puppies \& adolescent dogs (i.e. 2 months to 24 months) & 0 & 1 & $0 \%$ & $6 \%$ & 1 & $6 \%$ \\
\hline & TOTAL & 2 & 15 & $12 \%$ & $88 \%$ & 17 & $100 \%$ \\
\hline
\end{tabular}


Table 3. Overview of types of research designs, intervention types and learner undesired behaviors distributed across canine-related papers.

\begin{tabular}{|c|c|c|c|}
\hline Types of research designs & Intervention type & Count & Percent \\
\hline & Learner undesired behaviours & & \\
\hline \multirow[t]{16}{*}{ Case studies } & & 19 & $66 \%$ \\
\hline & Oral instruction/advice & 9 & $31 \%$ \\
\hline & Stereotypic behaviour & 2 & $7 \%$ \\
\hline & Separation-related behaviours & 2 & $7 \%$ \\
\hline & Aggressive behaviour & 2 & $7 \%$ \\
\hline & Fear \& anxiety & 2 & $7 \%$ \\
\hline & Behaviour problems & 1 & $3 \%$ \\
\hline & Oral instruction/advice + Written instruction/advice & 8 & $28 \%$ \\
\hline & Fear \& anxiety & 4 & $14 \%$ \\
\hline & Separation-related behaviours & 2 & $7 \%$ \\
\hline & Stereotypic behaviour & 1 & $3 \%$ \\
\hline & Aggressive behaviour & 1 & $3 \%$ \\
\hline & Oral instruction/advice + Modelling & 1 & $3 \%$ \\
\hline & Hyperactivity & 1 & $3 \%$ \\
\hline & Package & 1 & $3 \%$ \\
\hline & Separation-related behaviours & 1 & $3 \%$ \\
\hline \multirow[t]{13}{*}{ Group designs } & & 8 & $28 \%$ \\
\hline & Package & 2 & $7 \%$ \\
\hline & Separation-related behaviours & 1 & $3 \%$ \\
\hline & Fear \& anxiety & 1 & $3 \%$ \\
\hline & Oral instruction/advice + Written instruction/advice & 2 & $7 \%$ \\
\hline & Separation-related behaviours & 2 & $7 \%$ \\
\hline & Obedience training + Quality time & 1 & $3 \%$ \\
\hline & Separation-related behaviours & 1 & $3 \%$ \\
\hline & Behaviour problems & 1 & $3 \%$ \\
\hline & Written instruction/advice & 1 & $3 \%$ \\
\hline & Separation-related behaviours & 1 & $3 \%$ \\
\hline & Oral instruction/advice & 1 & $3 \%$ \\
\hline & Not clearly stated & 1 & $3 \%$ \\
\hline \multirow[t]{5}{*}{ Single-case designs } & & 2 & $7 \%$ \\
\hline & Package & 2 & $7 \%$ \\
\hline & Separation-related behaviours & 1 & $3 \%$ \\
\hline & Aggressive behaviour & 1 & $3 \%$ \\
\hline & TOTAL & 29 & $100 \%$ \\
\hline
\end{tabular}


Table 4. Overview of types of research designs, intervention types and learner undesired behaviors distributed across human-related papers.

\begin{tabular}{|c|c|c|c|}
\hline Types of research designs & Intervention type & Count & Percentage \\
\hline & Learner undesired behaviours & & \\
\hline \multirow[t]{29}{*}{ Single-case designs } & & 26 & $57 \%$ \\
\hline & Package & 17 & $37 \%$ \\
\hline & Undesired behaviour during meal times & 3 & $7 \%$ \\
\hline & Language delays & 3 & $7 \%$ \\
\hline & Not clearly stated & 2 & $4 \%$ \\
\hline & Behaviour problems & 2 & $4 \%$ \\
\hline & Non-compliance \& oppositional behaviour & 2 & $4 \%$ \\
\hline & Language/communication \& motor skill deficits & 2 & $4 \%$ \\
\hline & Oppositional behaviour & 1 & $2 \%$ \\
\hline & Behavioural deficits & 1 & $2 \%$ \\
\hline & Autism Spectrum Disorder \& language delays & 1 & $2 \%$ \\
\hline & Package + Video modelling & 1 & $2 \%$ \\
\hline & Not clearly stated & 1 & $2 \%$ \\
\hline & Modelling + Package & 1 & $2 \%$ \\
\hline & Behaviour problems & 1 & $2 \%$ \\
\hline & Written instruction/advice + Video modelling + Feedback + Modelling & 1 & $2 \%$ \\
\hline & Undesired behaviour during meal times & 1 & $2 \%$ \\
\hline & Package + Feedback & 1 & $2 \%$ \\
\hline & Deficits in language, social interaction \& academic skills & 1 & $2 \%$ \\
\hline & Written instruction/advice + Video modelling & 1 & $2 \%$ \\
\hline & Not clearly stated & 1 & $2 \%$ \\
\hline & Written instruction/advice + Modelling $\&$ role play & 1 & $2 \%$ \\
\hline & Not clearly stated & 1 & $2 \%$ \\
\hline & Written instruction/advice & 1 & $2 \%$ \\
\hline & Fear \& anxiety & 1 & $2 \%$ \\
\hline & Feedback & 1 & $2 \%$ \\
\hline & Autism Spectrum Disorder \& language delays & 1 & $2 \%$ \\
\hline & Oral instruction/advice + Package & 1 & $2 \%$ \\
\hline & Language delays & 1 & $2 \%$ \\
\hline \multirow[t]{13}{*}{ Group designs } & & 18 & $39 \%$ \\
\hline & Package & 16 & $35 \%$ \\
\hline & Not clearly stated & 6 & $13 \%$ \\
\hline & Behaviour problems & 3 & $7 \%$ \\
\hline & Autism Spectrum Disorder \& language delays & 2 & $4 \%$ \\
\hline & Oppositional behaviour & 2 & $4 \%$ \\
\hline & Inattantive \& hyperactive symptoms & 1 & $2 \%$ \\
\hline & Deficits in language, social interaction \& academic skills & 1 & $2 \%$ \\
\hline & Fear \& anxiety & 1 & $2 \%$ \\
\hline & Oral instruction/advice + Modelling & 1 & $2 \%$ \\
\hline & Not clearly stated & 1 & $2 \%$ \\
\hline & Package + Written instruction/advice + Oral instruction/advice & 1 & $2 \%$ \\
\hline & Not clearly stated & 1 & $2 \%$ \\
\hline \multirow[t]{6}{*}{ Case studies } & & 2 & $4 \%$ \\
\hline & Oral instruction/advice + Modelling + Feedback & 1 & $2 \%$ \\
\hline & Behavioural deficits & 1 & $2 \%$ \\
\hline & Package & 1 & $2 \%$ \\
\hline & Not clearly stated & 1 & $2 \%$ \\
\hline & TOTAL & 46 & $100 \%$ \\
\hline
\end{tabular}


Table 5. Overview of distribution of caregiver training outcomes displayed by type of research designs and intervention types for canine-related studies.

\begin{tabular}{|c|c|c|c|}
\hline Types of research designs & Outcome & Total & Percentage \\
\hline & Intervention type & & \\
\hline \multirow[t]{11}{*}{ Case studies } & & 19 & $66 \%$ \\
\hline & Not clearly stated & 13 & $45 \%$ \\
\hline & Oral instruction/advice & 7 & $24 \%$ \\
\hline & Oral instruction/advice + Written instruction/advice & 5 & $17 \%$ \\
\hline & Package & 1 & $3 \%$ \\
\hline & Positive & 4 & $14 \%$ \\
\hline & Oral instruction/advice & 2 & $7 \%$ \\
\hline & Oral instruction/advice + Modelling & 1 & $3 \%$ \\
\hline & Oral instruction/advice + Written instruction/advice & 1 & $3 \%$ \\
\hline & Mixed & 2 & $7 \%$ \\
\hline & Oral instruction/advice + Written instruction/advice & 2 & $7 \%$ \\
\hline \multirow[t]{9}{*}{ Group designs } & & 8 & $28 \%$ \\
\hline & Not clearly stated & 6 & $21 \%$ \\
\hline & Package & 2 & $7 \%$ \\
\hline & Oral instruction/advice + Written instruction/advice & 2 & $7 \%$ \\
\hline & Obedience training + Quality time & 1 & $3 \%$ \\
\hline & Mixed & 1 & $3 \%$ \\
\hline & Written instruction/advice & 1 & $3 \%$ \\
\hline & Positive & 1 & $3 \%$ \\
\hline & Oral instruction/advice & 1 & $3 \%$ \\
\hline \multirow[t]{6}{*}{ Single-case designs } & & 2 & $7 \%$ \\
\hline & Not clearly stated & 1 & $3 \%$ \\
\hline & Package & 1 & $3 \%$ \\
\hline & Positive & 1 & $3 \%$ \\
\hline & Package & 1 & $3 \%$ \\
\hline & TOTAL & 29 & $100 \%$ \\
\hline
\end{tabular}


Table 6. Overview of distribution of caregiver training outcomes displayed by type of research designs and intervention types for human-related studies.

\begin{tabular}{|c|c|c|c|}
\hline Types of research designs & Outcome & Total & Percentage \\
\hline & Intervention type & & \\
\hline \multirow{16}{*}{ Single-case designs } & & 26 & $57 \%$ \\
\hline & Positive & 21 & $46 \%$ \\
\hline & Package & 14 & $30 \%$ \\
\hline & Modelling + Package & 1 & $2 \%$ \\
\hline & Package + Video modelling & 1 & $2 \%$ \\
\hline & Written instruction/advice + Video modelling & 1 & $2 \%$ \\
\hline & Written instruction/advice + Modelling \& role play & 1 & $2 \%$ \\
\hline & Package + Feedback & 1 & $2 \%$ \\
\hline & Feedback & 1 & $2 \%$ \\
\hline & Oral instruction/advice + Package & 1 & $2 \%$ \\
\hline & Mixed & 3 & $7 \%$ \\
\hline & Package & 2 & $4 \%$ \\
\hline & Written instruction/advice + Video modelling + Feedback + Modelling & 1 & $2 \%$ \\
\hline & Not clearly stated & 2 & $4 \%$ \\
\hline & Written instruction/advice & 1 & $2 \%$ \\
\hline & Package & 1 & $2 \%$ \\
\hline \multirow[t]{9}{*}{ Group designs } & & 18 & $39 \%$ \\
\hline & Positive & 13 & $28 \%$ \\
\hline & Package & 11 & $24 \%$ \\
\hline & Oral instruction/advice + Modelling & 1 & $2 \%$ \\
\hline & Package + Written instruction/advice + Oral instruction/advice & 1 & $2 \%$ \\
\hline & Not clearly stated & 4 & $9 \%$ \\
\hline & Package & 4 & $9 \%$ \\
\hline & Mixed & 1 & $2 \%$ \\
\hline & Package & 1 & $2 \%$ \\
\hline \multirow[t]{5}{*}{ Case studies } & & 2 & $4 \%$ \\
\hline & Positive & 2 & $4 \%$ \\
\hline & Oral instruction/advice + Modelling + Feedback & 1 & $2 \%$ \\
\hline & Package & 1 & $2 \%$ \\
\hline & TOTAL & 46 & $100 \%$ \\
\hline
\end{tabular}


Table 7. Learner outcomes across research designs and caregiver training for canine-related studies.

\begin{tabular}{|c|c|c|c|}
\hline Types of research designs & Learner outcome & Total & Percentage \\
\hline & Caregiver training approach & & \\
\hline \multirow[t]{12}{*}{ Case studies } & & 19 & $66 \%$ \\
\hline & Decrease undesired behaviour & 9 & $31 \%$ \\
\hline & Oral instruction/advice & 6 & $21 \%$ \\
\hline & Oral instruction/advice + Written instruction/advice & 2 & $7 \%$ \\
\hline & Oral instruction/advice + Modelling & 1 & $3 \%$ \\
\hline & Mixed & 7 & $24 \%$ \\
\hline & Oral instruction/advice + Written instruction/advice & 5 & $17 \%$ \\
\hline & Oral instruction/advice & 2 & $7 \%$ \\
\hline & Increase desired behaviour & 3 & $10 \%$ \\
\hline & Oral instruction/advice & 1 & $3 \%$ \\
\hline & Oral instruction/advice + Written instruction/advice & 1 & $3 \%$ \\
\hline & Package & 1 & $3 \%$ \\
\hline \multirow[t]{9}{*}{ Group designs } & & 8 & $28 \%$ \\
\hline & Decrease undesired behaviour & 6 & $21 \%$ \\
\hline & Package & 2 & $7 \%$ \\
\hline & Obedience training + Quality time & 2 & $7 \%$ \\
\hline & Written instruction/advice & 1 & $3 \%$ \\
\hline & Oral instruction/advice + Written instruction/advice & 1 & $3 \%$ \\
\hline & Mixed & 2 & $7 \%$ \\
\hline & Oral instruction/advice + Written instruction/advice & 1 & $3 \%$ \\
\hline & Oral instruction/advice & 1 & $3 \%$ \\
\hline \multirow[t]{4}{*}{ Single-case designs } & & 2 & $7 \%$ \\
\hline & Decrease undesired behaviour & 2 & $7 \%$ \\
\hline & Package & 2 & $7 \%$ \\
\hline & TOTAL & 29 & $100 \%$ \\
\hline
\end{tabular}


Table 8. Learner outcomes across research designs and caregiver training for human-related studies.

\begin{tabular}{|c|c|c|c|}
\hline Types of research designs & Learner outcome & Total & Percentage \\
\hline & Caregiver training approach & & \\
\hline \multirow[t]{20}{*}{ Single-case designs } & & 26 & $57 \%$ \\
\hline & Increase desired behaviour & 10 & $22 \%$ \\
\hline & Package & 8 & $17 \%$ \\
\hline & Modelling + Package & 1 & $2 \%$ \\
\hline & Oral instruction/advice + Package & 1 & $2 \%$ \\
\hline & Decrease undesired behaviour & 7 & $15 \%$ \\
\hline & Package & 4 & $9 \%$ \\
\hline & Written instruction/advice + Video modelling + Feedback + Modelling & 1 & $2 \%$ \\
\hline & Feedback & 1 & $2 \%$ \\
\hline & Written instruction/advice & 1 & $2 \%$ \\
\hline & Not clearly stated & 5 & $11 \%$ \\
\hline & Package & 2 & $4 \%$ \\
\hline & Written instruction/advice + Video modelling & 1 & $2 \%$ \\
\hline & Package + Video modelling & 1 & $2 \%$ \\
\hline & Written instruction/advice + Modelling $\&$ role play & 1 & $2 \%$ \\
\hline & Mixed & 3 & $7 \%$ \\
\hline & Package & 2 & $4 \%$ \\
\hline & Package + Feedback & 1 & $2 \%$ \\
\hline & Increase undesired behaviour & 1 & $2 \%$ \\
\hline & Package & 1 & $2 \%$ \\
\hline \multirow[t]{11}{*}{ Group designs } & & 18 & $39 \%$ \\
\hline & Not clearly stated & 7 & $15 \%$ \\
\hline & Package & 5 & $11 \%$ \\
\hline & Oral instruction/advice + Modelling & 1 & $2 \%$ \\
\hline & Package + Written instruction/advice + Oral instruction/advice & 1 & $2 \%$ \\
\hline & Decrease undesired behaviour & 6 & $13 \%$ \\
\hline & Package & 6 & $13 \%$ \\
\hline & Increase desired behaviour & 3 & $7 \%$ \\
\hline & Package & 3 & $7 \%$ \\
\hline & Mixed & 2 & $4 \%$ \\
\hline & Package & 2 & $4 \%$ \\
\hline \multirow[t]{6}{*}{ Case studies } & & 2 & $4 \%$ \\
\hline & Not clearly stated & 1 & $2 \%$ \\
\hline & Package & 1 & $2 \%$ \\
\hline & Increase desired behaviour & 1 & $2 \%$ \\
\hline & Oral instruction/advice + Modelling + Feedback & 1 & $2 \%$ \\
\hline & TOTAL & 46 & $100 \%$ \\
\hline
\end{tabular}


Table 9. Meta-regression results across all six variables.

\begin{tabular}{|l|l|l|l|l|}
\hline $\begin{array}{l}\text { Moderator } \\
\text { variables }\end{array}$ & $\begin{array}{l}\text { Number of } \\
\text { covariates }\end{array}$ & $Q$ & $p$-value & $R^{2}(\%)$ \\
\hline $\begin{array}{l}\text { Intervention } \\
\text { type }\end{array}$ & 6 & 4.43 & 0.48 & 1 \\
\hline Study design & 3 & 1.4 & 0.49 & 0 \\
\hline Learner species & 2 & 10.98 & $0.0009^{*}$ & 25 \\
\hline Learner age & 5 & 15.39 & $0.004^{*}$ & 29 \\
\hline Publication year & 2 & 9.25 & $0.0024^{*}$ & 4 \\
\hline Study duration & 5 & 11.67 & $0.02^{*}$ & 8 \\
\hline
\end{tabular}

Note. $Q$ is a statistic used to test the significance of the meta-regression. Statistically significant $p$-values (i.e., $p<0.05$ ) are indicated by an asterisk. $R^{2}$ is the proportion of variance explained by the moderator. 


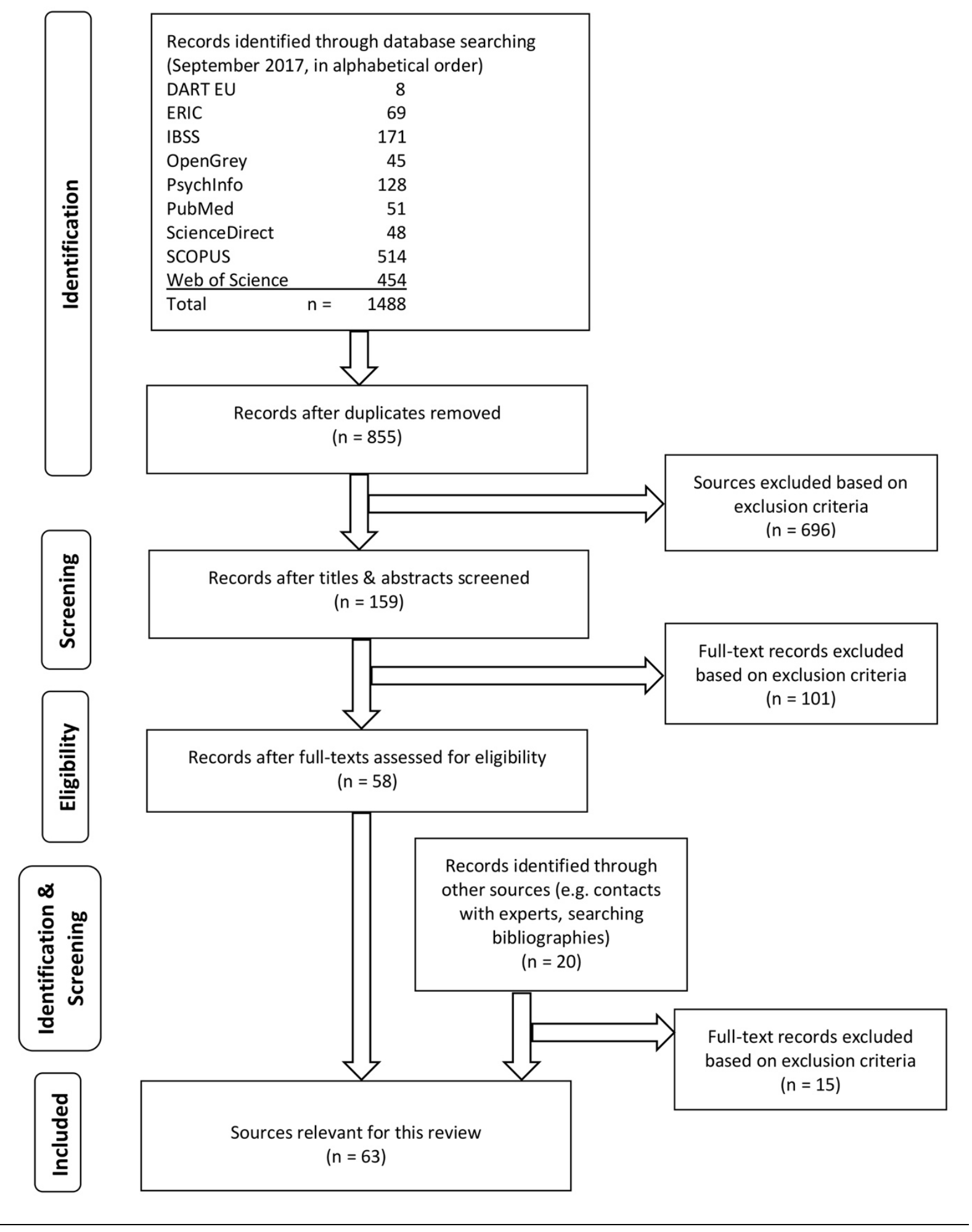


Hedges's $g$ and $95 \% \mathrm{C}$

$\begin{array}{ll}\text { Blackwell et al. (2006) } & \text { PG } \\ \text { Brody et al. (2006) } & \text { PG } \\ \text { Brody et al. (2006) } & \text { PG } \\ \text { Brody et al. (2006) } & \text { PG } \\ \text { Brody et al. (2006) } & \text { PG } \\ \text { Crowell-Davis et al. (2003) } & \text { PG } \\ \text { Jang et al. (2012) } & \text { PG } \\ \text { Lindgren et al. (2016) } & \text { PG } \\ \text { Lindgren et al. (2016) } & \text { PG } \\ \text { Lindgren et al. (2016) } & \text { PG } \\ \text { Lucyshyn et al. (2015) } & \text { PG } \\ \text { Minjarez-Boettcher et al. (2011) } & \text { PG } \\ \text { Minjarez-Boeetcher et al. (2011) } & \text { PG } \\ \text { Reitzel et al. (2013) } & \text { PG } \\ \text { Reitzel et al. (2013) } & \text { PG } \\ \text { Reitzel et al. (2013) } & \text { PG } \\ \text { Rostad et al. (2017) } & \text { PG } \\ \text { Rudy et al. (2017) } & \text { PG } \\ \text { Rudy et al. (2017) } & \text { PG } \\ \text { Rudy et al. (2017) } & \text { PG } \\ \text { Schoenfelder et al. (2013) } & \text { PG } \\ \text { Schoenfelder et al. (2013) } & \text { PG } \\ \text { Schoenfelder et al. (2013) } & \text { PG } \\ \text { Schoenfelder et al. (2013) } & \text { PG } \\ \text { Schoenfelder et al. (2013) } & \text { PG } \\ \text { Pelham et al. (1980) } & \text { PG } \\ \text { Pelham et al. (1980) } & \text { PG } \\ \text { Pelham et al. (1980) } & \text { PG } \\ \text { Pelham et al. (1980) } & \text { PG } \\ \text { Pelham et al. (1980) } & \text { PG } \\ \text { Pelham et al. (1980) } & \text { PG } \\ \text { Pelham et al. (1980) } & \text { PG } \\ \end{array}$

Efficacy of Treatment Questionnaire Expectations for Alcohol Use Score Involved-Vigilant Parenting Score

Racial Socialization Score

Sexual Communication Score

Storm Phobia Assessment Score

e-Learning Multipl Choice

in Home Therapy Observation

Telehealth Clinic Observation

Telehealth Home Observation

Number of Problem Behaviours

Pivotal Response Training Fidelity

Pivotal Response Training Utterances

Caregiver Strain Questionnaire

Knowledge Questionnaire

Sense of Competence Questionnaire

Number of Hazards

Anxiety Disorder Interview

Clinical Improvement Rating

Pediatric Anxienty Rating

Depression Questionnair

Grief Questionnaire

Learner Externalizing Questionnaire

Learner Internalizing Questionnaire

Positive Parenting Questionnaire

Activity Scale WWP

Aggressive-Conduct Questionnaire

Count Correct Problems Completed

Parent Command Observation

Parent Praise Observation

Percentage On-Task Observation

Problem Behaviour Rating

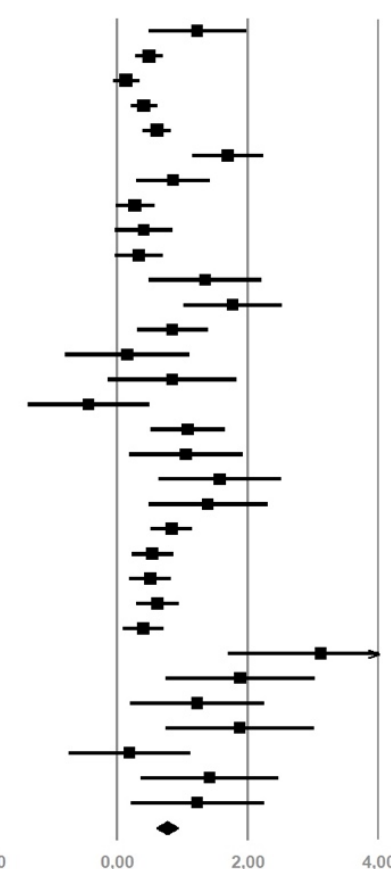

dges's Lower Upper

$g$ limit limit p-Value

$\begin{array}{lllll}1,229 & 0,489 & 1,968 & 0,001\end{array}$

$\begin{array}{llll}0,490 & 0,285 & 0,696 & 0,000\end{array}$

$\begin{array}{llll}0,139 & -0,056 & 0,334 & 0,162\end{array}$

$\begin{array}{llll}0,413 & 0,211 & 0,616 & 0,000\end{array}$

$\begin{array}{lllll}1,696 & 1,159 & 2,233 & 0,000\end{array}$

$\begin{array}{lllll}0,857 & 0,297 & 1,417 & 0,003\end{array}$

$\begin{array}{llllll}0,406 & -0,033 & 0,845 & 0,072\end{array}$

$\begin{array}{llll}0,330 & -0,029 & 0,688 & 0,071\end{array}$

$\begin{array}{llll}1,347 & 0,491 & 2,202 & 0,002\end{array}$

$\begin{array}{llll}1,767 & 1,020 & 2,514 & 0,000\end{array}$

$\begin{array}{lllll}0,848 & 0,313 & 1,383 & 0,002\end{array}$

$\begin{array}{llll}0,155 & -0,787 & 1,098 & 0,747\end{array}$

$\begin{array}{llll}0,840 & -0,147 & 1,827 & 0,095\end{array}$

$\begin{array}{lllll}-0,434 & -1,364 & 0,496 & 0,360\end{array}$

$\begin{array}{lllll}1,083 & 0,522 & 1,645 & 0,000\end{array}$

$\begin{array}{lllll}1,083 & 0,522 & 1,045 & 0,000\end{array}$

$\begin{array}{lllll}1,055 & 0,190 & 1,921 & 0,017 \\ 1,572 & 0,041 & 2,503 & 0,001\end{array}$

$\begin{array}{llllll}1,572 & 0,041 & 2,503 & 0,001\end{array}$

$\begin{array}{lllll}1,393 & 0,487 & 2,299 & 0,003\end{array}$

$\begin{array}{lllll}0,833 & 0,516 & 1,149 & 0,000\end{array}$

$\begin{array}{llll}0,540 & 0,228 & 0,853 & 0,001\end{array}$

$\begin{array}{llll}0,504 & 0,193 & 0,816 & 0,002\end{array}$

$\begin{array}{llll}0,618 & 0,303 & 0,933 & 0,000\end{array}$

$\begin{array}{lllll}0,396 & 0,089 & 0,703 & 0,011\end{array}$

$\begin{array}{lllll}3,120 & 1,696 & 4,544 & 0,000\end{array}$

$\begin{array}{llll}1,886 & 0,752 & 3,020 & 0,001\end{array}$

$\begin{array}{llll}1,224 & 0,205 & 2,243 & 0,019\end{array}$

$\begin{array}{lllll}1,224 & 0,205 & 2,243 & 0,019\end{array}$

$\begin{array}{lllll}1,877 & 0,745 & 3,009 & 0,001\end{array}$

$\begin{array}{lllll}0,189 & 0,740 & 1,118 & 0,690\end{array}$

$\begin{array}{lllll}1,418 & 0,369 & 2,467 & 0,008\end{array}$

$\begin{array}{lllll}1,229 & 0,209 & 2,249 & 0,018\end{array}$

$\begin{array}{llll}0,761 & 0,603 & 0,919 & 0,000\end{array}$ 


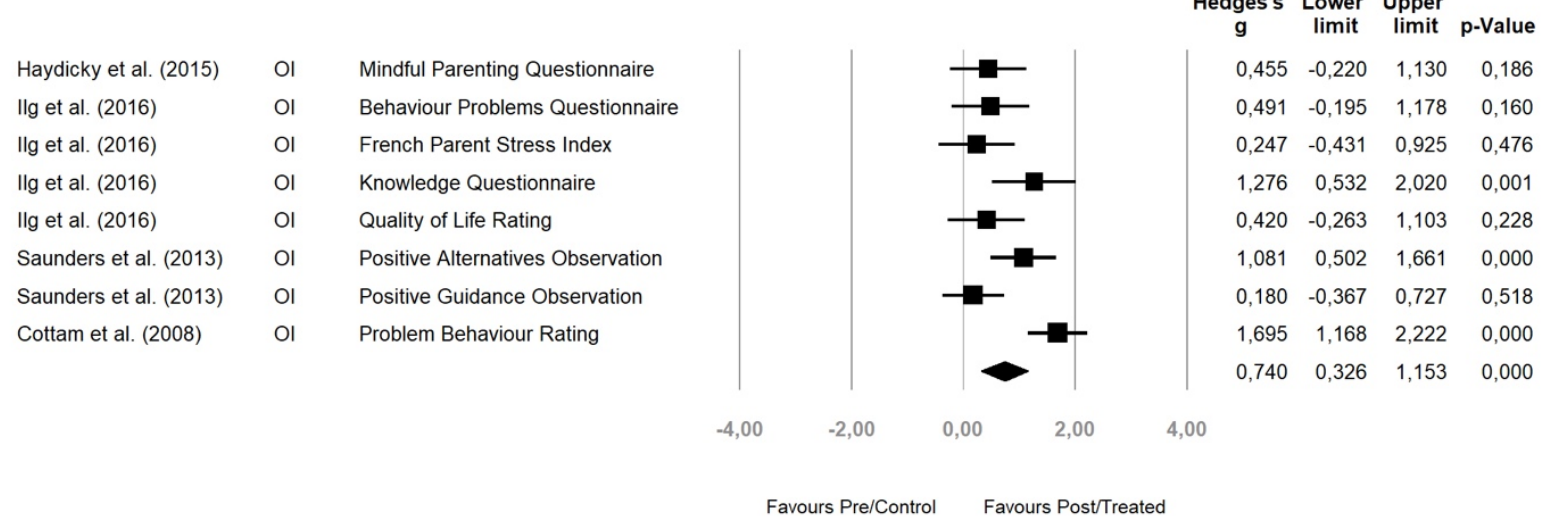




\section{Study name}

Clark et al. (1993)

Blackwell et al. (2006)

Blackwell et al. (2016)

Brody et al. (2006)

Crowell-Davis et al. (2003)

Haydicky et al. (2015)

Ilg et al. (2016)

Jang et al. (2012)

Lindgren et al. (2016)

Lucyshyn et al. (2015)

Minjarez-Boettcher et al. (2011)

Reitzel et al. (2013)

Rostad et al. (2017)

Rudy et al. (2017)

Saunders et al. (2013)

Schoenfelder et al. (2013)

Pelham et al. (1980)

Cottam et al. (2008)

\section{Hedges's g and $95 \% \mathrm{CI}$}
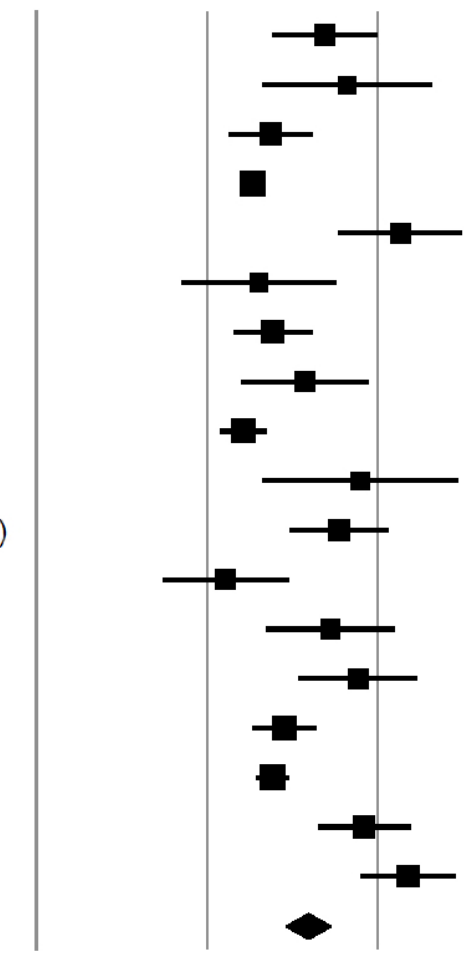

$\begin{array}{llll}-1,50 & 0,00 & 1,50 & 3,00\end{array}$
Hedges's Lower Upper

g

$\begin{array}{llll}1,033 & 0,571 & 1,495 & 0,000\end{array}$

$\begin{array}{llll}1,229 & 0,489 & 1,968 & 0,001\end{array}$

$\begin{array}{llll}0,558 & 0,196 & 0,921 & 0,003\end{array}$

$\begin{array}{llll}0,403 & 0,301 & 0,505 & 0,000\end{array}$

$1,696 \quad 1,159 \quad 2,233 \quad 0,000$

$\begin{array}{llll}0,455 & -0,220 & 1,130 & 0,186\end{array}$

$\begin{array}{llll}0,580 & 0,232 & 0,928 & 0,001\end{array}$

$0,857 \quad 0,297 \quad 1,417 \quad 0,003$

$\begin{array}{llll}0,318 & 0,116 & 0,521 & 0,002\end{array}$

$\begin{array}{llll}1,347 & 0,491 & 2,202 & 0,002\end{array}$

$\begin{array}{llll}1,159 & 0,725 & 1,594 & 0,000\end{array}$

$\begin{array}{llll}0,162 & -0,388 & 0,712 & 0,564\end{array}$

$\begin{array}{llll}1,083 & 0,522 & 1,645 & 0,000\end{array}$

$\begin{array}{llll}1,327 & 0,808 & 1,847 & 0,000\end{array}$

$\begin{array}{llll}0,678 & 0,395 & 0,961 & 0,000\end{array}$

$\begin{array}{llll}0,575 & 0,436 & 0,715 & 0,000\end{array}$

$\begin{array}{llll}1,380 & 0,973 & 1,787 & 0,000\end{array}$

$\begin{array}{llll}1,766 & 1,355 & 2,178 & 0,000\end{array}$

$\begin{array}{llll}0,880 & 0,683 & 1,078 & 0,000\end{array}$

Favours Pre/Control Favours Post/Treated 
Regression of Hedges's g on Learner species

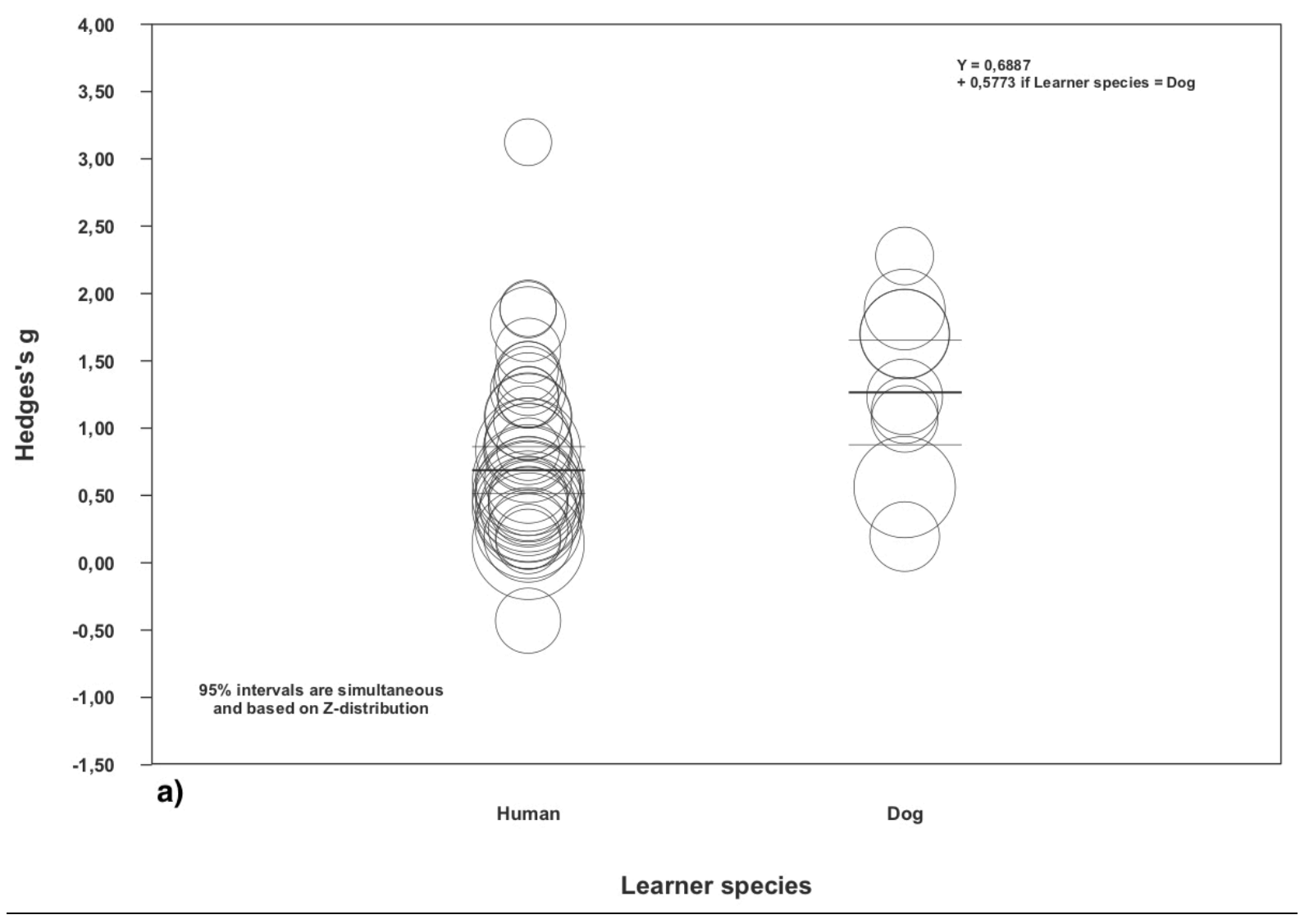




\section{Regression of Hedges's g on Learner age}

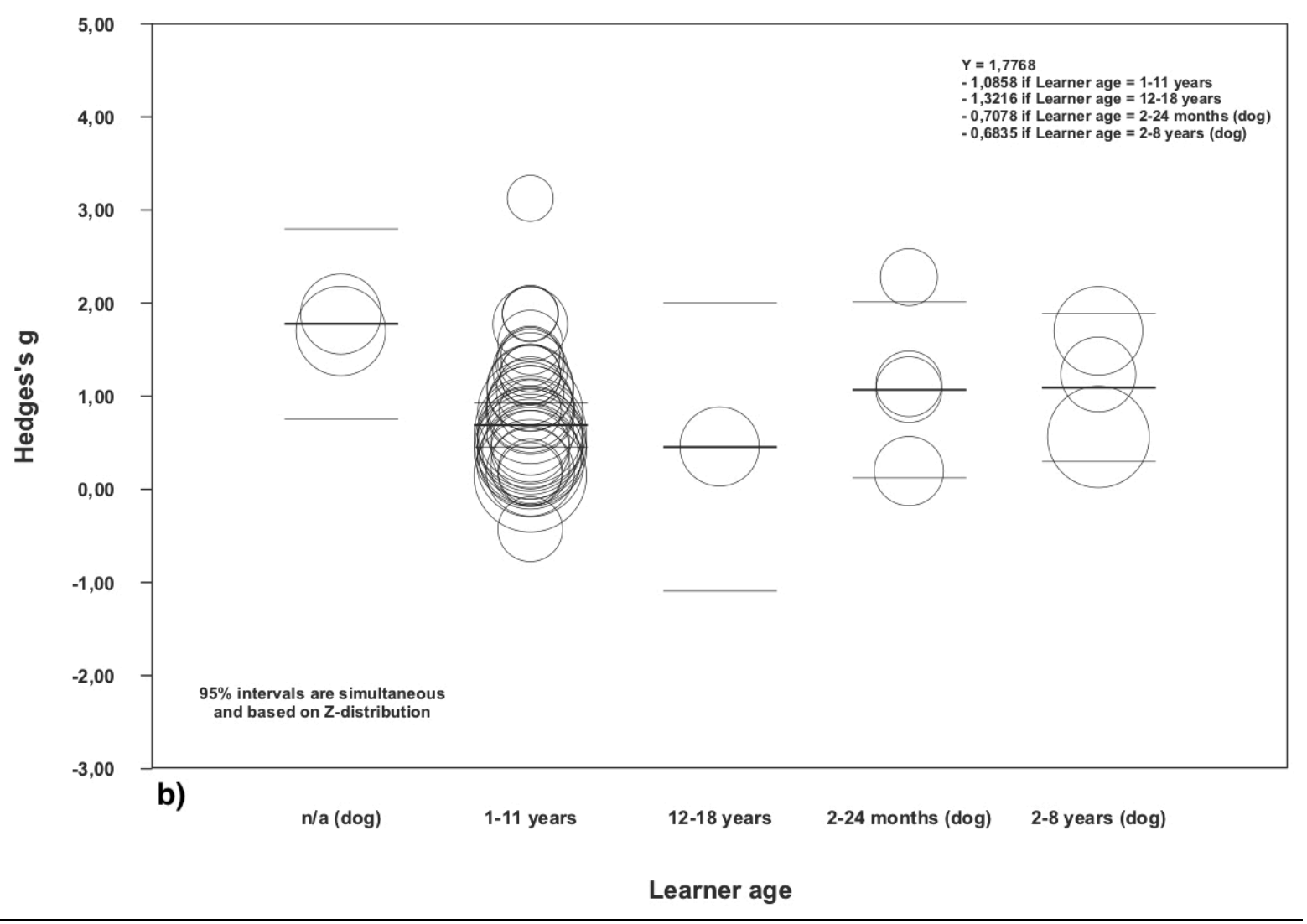




\section{Regression of Hedges's g on Publication year}

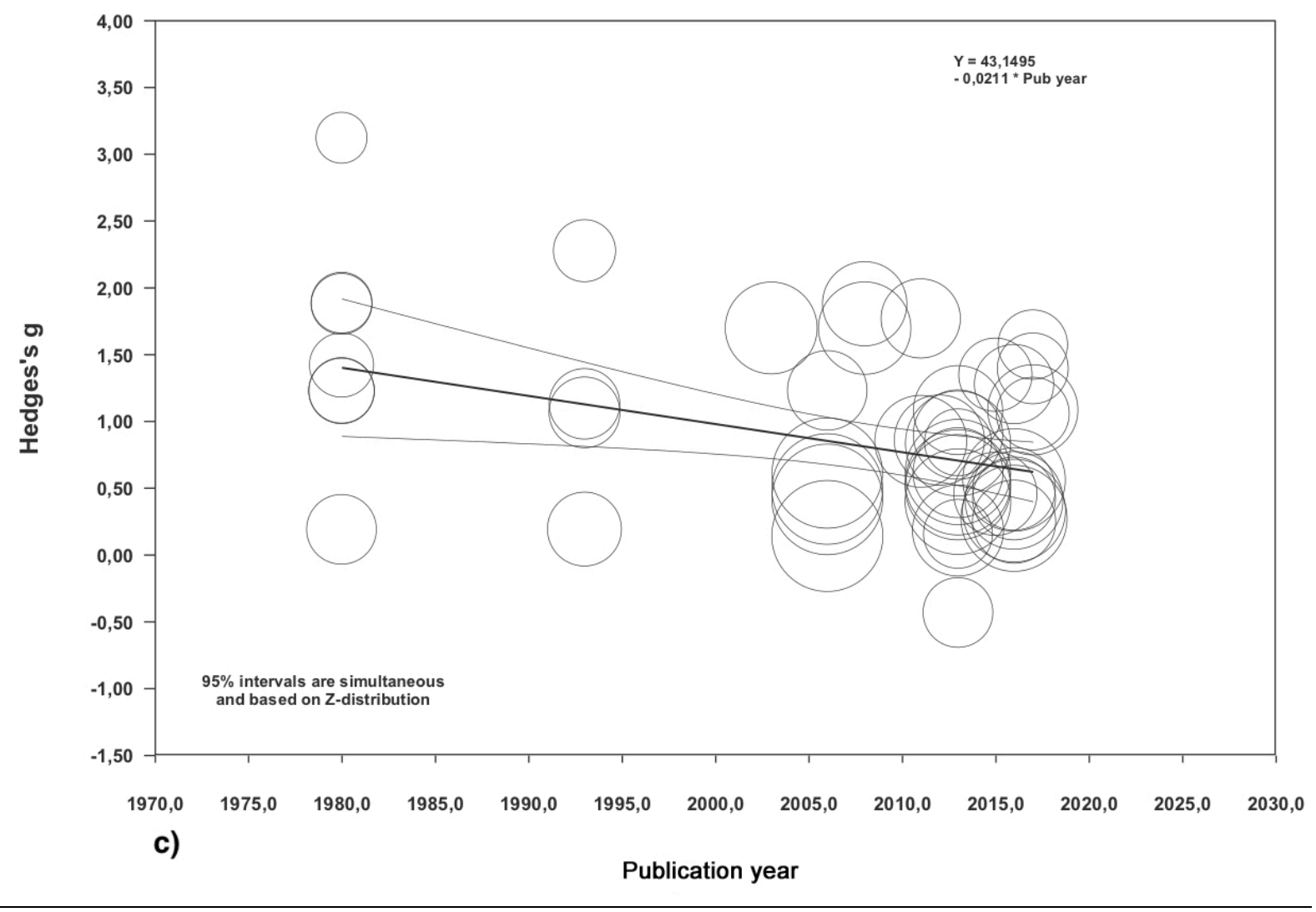


Regression of Hedges's g on Study duration

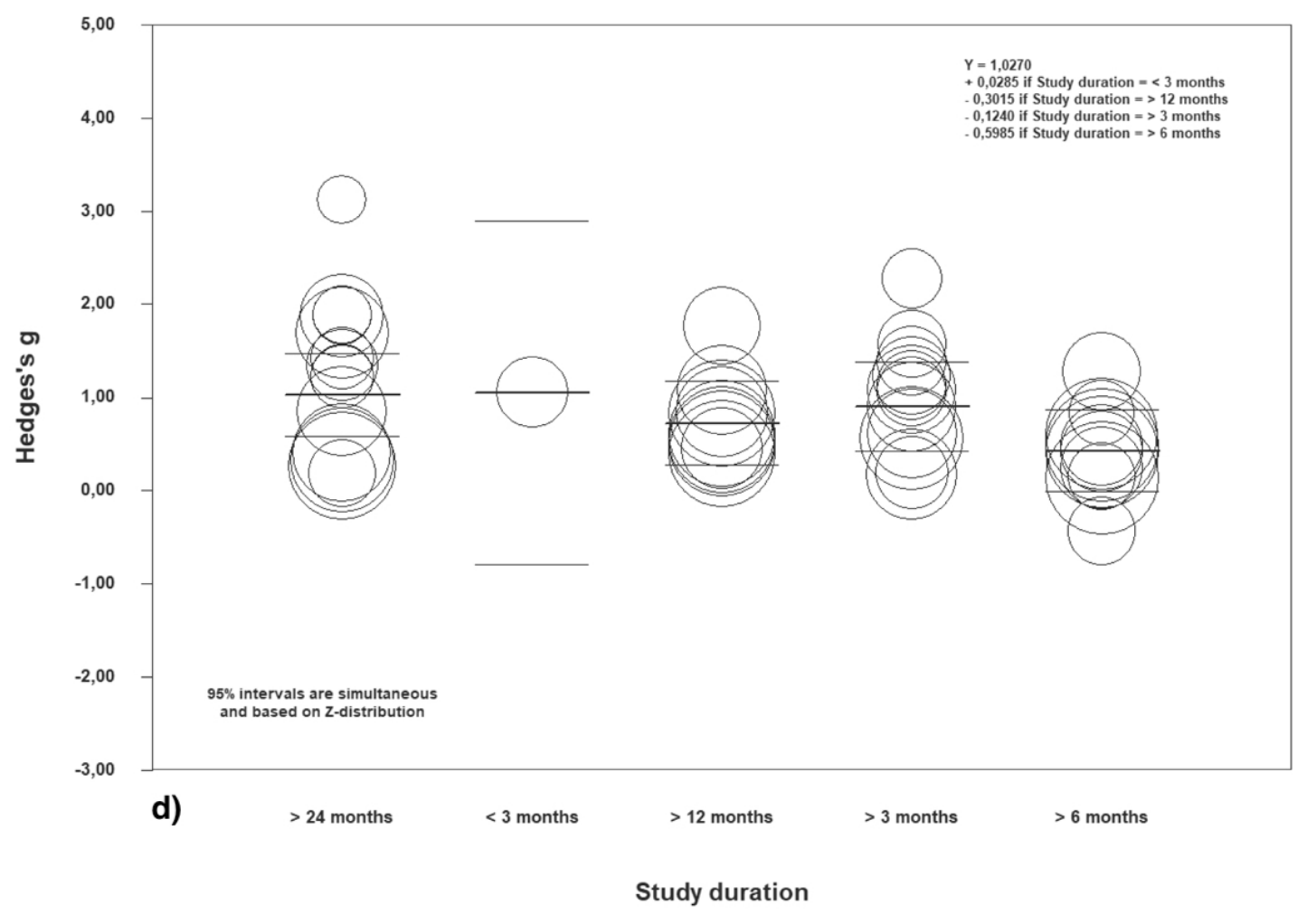


Funnel Plot of Standard Error by Hedges's g

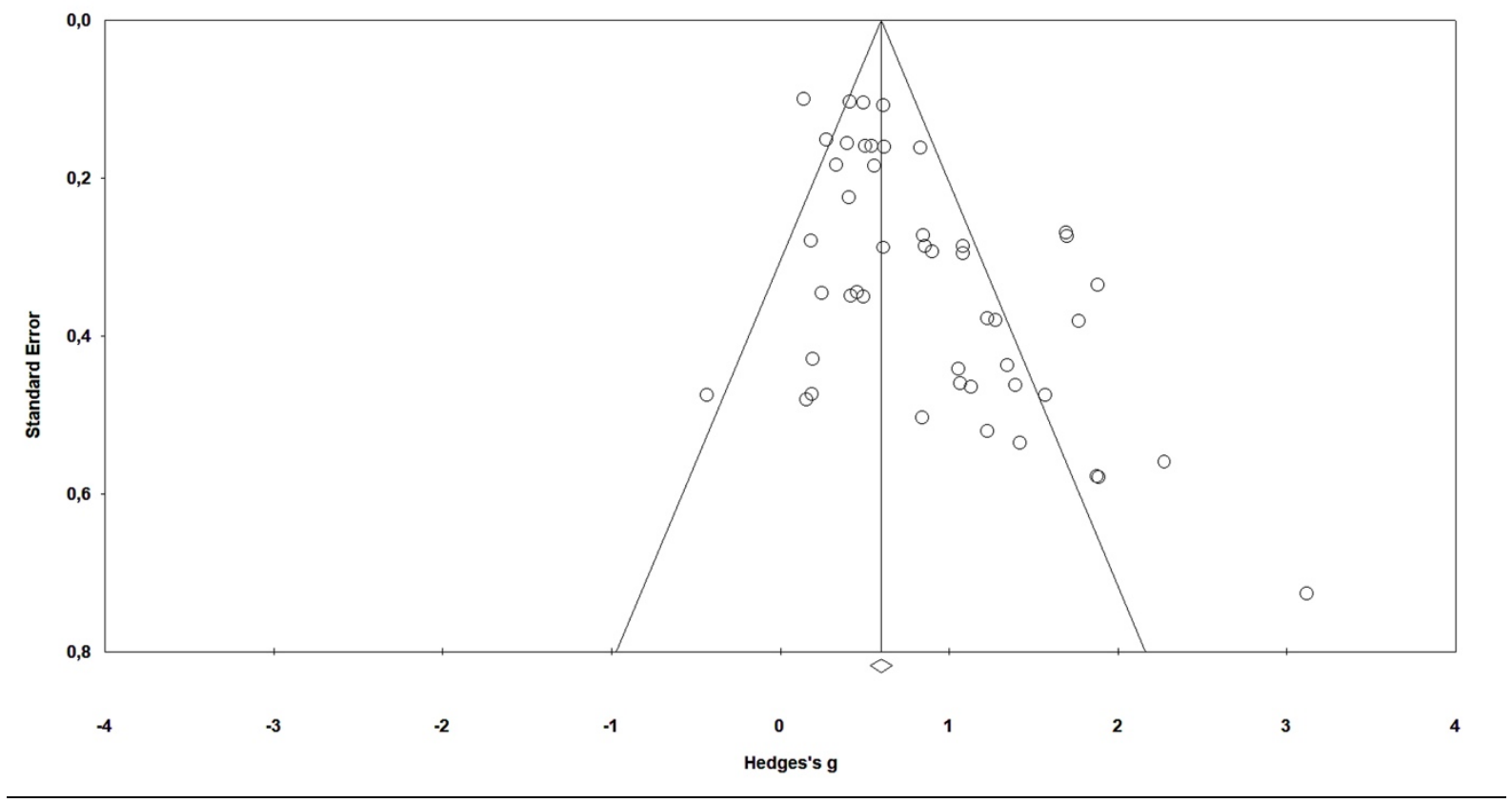

66 
Figure captions

Figure 1. Flow diagram of the different stages during the selection process for identification of studies eligible for further (statistical) analysis (adapted after PRISMA guidelines - Liberati et al., 2009; Moher et al., 2009).

Figure 2. Package (PG) forest plot and effect size statistics. Note. Measurement column shows how the dependent variables were measured (e.g. questionnaires or direct observations). The diamond-shaped data point at the bottom of the forest plot represents the summary effect size for all PGs.

Figure 3. Oral instruction/advice (OI) forest plot and effect size statistics. Note. Measurement column shows how the dependent variables were measured. The diamond-shaped data point at the bottom of the forest plot represents the summary effect size for all OI.

Figure 4. Effect size statistics and forest plot for all included studies. Note. The diamondshaped data point at the bottom of the forest plot represents the overall effect size estimation across all studies.

Figure 5. Scatterplots of meta-regressions for statistically significant results: a) Learner species across all measures; b) Learner age across all measures; c) Years of publication for respective studies. The regression line shows that the average effect of studies in the total sample decreases; and d) Duration of research across measures.

Note. The bold lines represent the average effect for the respective covariate, while the thin lines represent lower and upper 95\% CIs. The circles represent individual measures or studies, with smaller circles representing measures or studies with smaller standard errors.

Figure 6. Funnel plot showing the distribution of all included studies. 